University of Wollongong

Research Online

Faculty of Engineering and Information

Faculty of Engineering and Information

Sciences - Papers: Part A

Sciences

2015

Multi-period liner ship fleet planning with dependent uncertain container shipment demand

Qiang Meng

National University of Singapore

Tingsong Wang

Wuhan University, emswangts@whu.edu.cn

Shuaian Wang

University of Wollongong, shuaian@uow.edu.au

Follow this and additional works at: https://ro.uow.edu.au/eispapers

Part of the Engineering Commons, and the Science and Technology Studies Commons

Research Online is the open access institutional repository for the University of Wollongong. For further information contact the UOW Library: research-pubs@uow.edu.au 


\title{
Multi-period liner ship fleet planning with dependent uncertain container shipment demand
}

\begin{abstract}
This paper deals with a realistic multi-period liner ship fleet planning problem by incorporating stochastic dependency of the random and period-dependent container shipment demand. This problem is formulated as a multi-period stochastic programming model with a sequence of interrelated two-stage stochastic programming (2SSP) problems characterized ship fleet planning in each single period. A solution method integrating dual decomposition and Lagrangian relaxation method is designed for solving the developed model. Numerical experiments are carried out to assess applicability and performance of the proposed model and solution algorithm. The results further demonstrate importance of stochastic dependence of the uncertain container shipment demand.
\end{abstract}

\section{Keywords}

period, container, shipment, demand, liner, ship, fleet, planning, dependent, multi, uncertain

Disciplines

Engineering | Science and Technology Studies

\section{Publication Details}

Meng, Q., Wang, T. \& Wang, S. (2015). Multi-period liner ship fleet planning with dependent uncertain container shipment demand. Maritime Policy and Management: an international journal of shipping and port research, 42 (1), 43-67. 


\title{
Multi-period Liner Ship Fleet Planning with Dependent Uncertain Container
}

\section{Shipment Demand}

\author{
Qiang Meng ${ }^{1}$, Tingsong Wang ${ }^{2 *}$, Shuaian Wang ${ }^{3}$ \\ ${ }^{1}$ Department of Civil and Environmental Engineering, National University of Singapore, \\ Singapore, 117576 \\ ${ }^{2}$ School of Economics and Management, Wuhan University, Wuhan, China, 430072 \\ ${ }^{3}$ School of Mathematics and Applied Statistics, University of Wollongong, Wollongong,
} NSW 2522, Australia

\begin{abstract}
This paper deals with a realistic multi-period liner ship fleet planning problem by incorporating stochastic dependency of the random and period-dependent container shipment demand. This problem is formulated as a multi-period stochastic programming model with a sequence of interrelated two-stage stochastic programming problems characterized ship fleet planning in each single period. A solution method integrating dual decomposition and Lagrangian relaxation method is designed for solving the developed model. Numerical experiments are carried out to assess applicability and performance of the proposed model and solution algorithm. The results further demonstrate importance of stochastic dependence of the uncertain container shipment demand.
\end{abstract}

Keywords: multi-period liner ship fleet planning, uncertain container shipment demand, container transshipment, scenario tree, decision tree

\footnotetext{
* Corresponding author

E-mail: emswangts@whu.edu.cn (T. Wang)

Tel: +86-27-68753125

Fax: $+86-27-68754150$
} 


\section{INTRODUCTION}

A liner container shipping company (or container shipping liners) usually operates a heterogeneous fleet of ships with different size on couples of ship routes forming a shipping network with a regular service schedule, to transport containers among ports. Liner container shipping companies have been seeking for the optimization technology to create cost-effective plans for operating and upgrading their ship fleets. These plans aim to make capacity of a liner ship fleet effectively match container shipment demand. However, in a multi-period planning horizon, port to port container shipment demands could differ from one period to another. To cope with the period-dependent container shipment demand pattern, a liner container shipping company has to adjust its ship fleet plan including ship fleet size, mix and deployment, period-by-period, which is referred to in this paper as the multi-period liner ship fleet planning (MPLSFP) problem.

Traditional MPLSFP begins with a forecasted or estimated container shipment demand pattern for each single period using some demand forecasting techniques such as regression and time series models. However, a forecasted container shipment demand pattern as a necessary input of the MPLSFP problem can never be forecasted with complete confidence. It is almost impossible to precisely match estimated demand with the one realized. In other words, uncertainty of estimated container shipment demand should be incorporated into the MPLSFP problem. In reality, the container shipment demand at one period has effect on the future demand, which indicates that the container shipment demand is dependent on the demand in previous periods. Therefore, it is realistic and necessary to take the uncertainty and stochastic dependency of container shipment demand into account in the MPLSFP problem. It should be pointed out that the 
port-to-port container shipment demand is the hardest to estimate accurately, in comparison to other parameters such as miscellaneous costs and revenues.

Container transshipment operation should be also taken into account in the MPLSFP problem because transshipment of containers at hub ports is a typical container operation strategy adopted by liner container companies nowadays. As a consequence, about one third of the laden container throughput in the world in 2010 is made up of transshipped containers (Vernimmen, Dullaert, and Engelen, 2007). Container transshipment operation enables liner shipping companies to use large ships, calling at hub ports due to economies of scale in ship size (Cullinance and Khanna, 1999).

To the best of our knowledge, the MPLSFP problem taking into account container transshipment operations and stochastic dependency of random and period-dependent container shipment demand, is a new research issue with practical importance. This MPLSFP problem significantly expands the research scope of the classical MPLSFP problem which deals with the deterministic container shipment demand without container transshipment operations. The objective of this study is to tackle the MPLSFP problem with container transshipment and stochastic dependency of container shipment demand by building an appropriate optimization and designing an efficient solution method.

\subsection{Literature review}

Multi-period/long-term ship fleet planning problems have been studied for several decades. However, most of these studies make the assumption of deterministic shipment demand. Nicholson and Pullen are the pioneers in the field, developing a dynamic programming model for a ship fleet management problem that aimed to find the best sale and replacement policy, with the objective of maximizing the multi-period company 
assets (Nicholson and Pullen, 1971). They proposed a two-stage decision strategy: the first stage determines a priority order for selling a ship, based on its assessment of the net contribution to the objective function if it is sold in each year, regardless of the rate at which charter ships are taken on; the second stage uses the dynamic programming approach to find the optimal level of chartering for a given priority replacement order. An integer linear programming model was proposed for a multi-period liner ship fleet planning problem looking to determine the optimal fleet size, mix and ship-to-route allocation (Cho and Perakis, 1996). In this model, the fleet size and mix decisions are made at the beginning of the planning horizon and do not change within the planning horizon. In other words, the fleet size and mix decisions are the same for all the periods in the planning horizon. Therefore, it cannot characterize a realistic dynamic decision strategy: the fleet size, mix and ship-to-route allocation should be adjustable period-byperiod, since the container shipment demand is period-dependent. In other words, it is more rational and practical to assume that the fleet size, mix and ship-to-route allocation are period-dependent (dynamic) decisions rather than static ones. The multi-period liner shipping problem proposed by Cho and Perakis (1996) was reformulated as a dynamic programming model by Xie, Wang and Chen (2000). The multi-period planning horizon was divided into a number of single periods (each single period being one year). For each period, they used integer linear programming approach to determine the fleet size, mix and ship-to-route assignment incurring minimal cost. However, the annual operating cost and transportation capacity of each ship on each route were assumed constant. This assumption is unrealistic because the costs are voyage-dependent. For example, a ship sailing 20 voyages on a given route over a given year would certainly incur greater 
annual operating costs and have a greater transportation capacity than a ship that sails ten voyages on the same route. Recently, Meng and Wang (2011) proposed a realistic MPLSFP problem and formulated this problem as a scenario-based dynamic programming model. However, as well as the deterministic container shipment demand assumption, these studies reviewed above do not take container transshipment operations into account.

There have been some studies concentrating on the short-term liner ship fleet planning problems (see Ronen 1983, 1993; Christiansen, Fagerholt and Ronen, 2007; Christiansen et al. 2007). Perakis and Jaramillo (1991) proposed a linear programming model for a liner ship fleet planning problem. Later, they realized that the linear programming model may yield a real rather than an integer number of ships deployed on a ship route (Jaramillo and Perakis, 1991). They built an integer linear programming model for the same problem (Powell and Perakis, 1997). This model was improved and extended by S. Wang, T. Wang, and Meng (2011). It is noted that, once again, these studies all make the assumption of deterministic container shipment demand and fail to consider container transshipment. Meng and Wang (2010) developed a chance constrained programming model for a short-term liner ship fleet planning problem with uncertain container shipment demand. This uncertain container shipment demand can actually be transformed to deterministic demand. Moreover, container transshipment operations are not allowed in the model.

Mourão, Pato, and Paixão (2001) made the first attempt to consider the liner ship fleet deployment problem with container transshipment operations in a hypothetical huband-spoke $(H \& S)$ network with one pair of ports and two ship routes - one feeder route 
and one main route. All containers had to be transshipped at the hub port in the feeder route. Their model is too simple to reflect realistic ship fleet deployment. Wang and Meng (2012) studied a fleet deployment problem with transshipment and fixed container shipment demand. Meng and Wang (2012) investigated a fleet deployment problem with transhipment and week-dependent container demand. Nevertheless, the container demand in each week was assumed to be known. Meng, T. Wang, and S. Wang (2012) examined a fleet planning problem with transhipment uncertain demand. However, there was only one planning period and the demand was constant in the period. Some other researchers all addressed liner shipping service network design with container transshipment operations, including liner ship fleet deployment to some extent (Agarwal and Ergun, 2008), shipment demand assignment and empty container repositioning in liner shipping (Song et al., 2005; Dong and Song, 2009), liner shipping service optimization with reefer containers (Cheaitou and Cariouz, 2012). They all assumed deterministic container shipment demand.

Compared to the few relevant studies on the MPLSFP problem with uncertain container shipment demand, much research has been devoted to other problems under the assumption of uncertain multi-period demand, such as capacity expansion problems (Ahmed and Sahinidis, 2003), airline fleet composition and allocation problem (Listes and Dekker, 2005), multi-site production planning problem (Leung et al., 2007), portfolio management problems (Celikyurt and Özekici, 2007; Gülpinar and Rustem, 2007), and others. Their objectives are to minimize or maximize the expected value of a key variable, such as cost or profit, over a multi-period planning horizon, which is defined as the sum of the cost or profit in each single period. However, research methodologies used by 
these studies seldom involved the stochastic dependency of the uncertain multi-period demand. Shapiro and Philpott (2007) did in fact mention the dependency of uncertain demand in a multi-stage stochastic programming problem. Unfortunately, no application or study involving stochastic dependency has been reported so far.

\subsection{Contributions}

Although container transshipment operations and stochastic dependency of the period-dependent container shipment demand should have significant impact on liner ship fleet planning, they are not well addressed by the existing studies according to the above literature review. This paper will fist show that the procedure to determine a liner ship fleet plan with random and period-dependent container shipment demand can be formulated a decision tree. It proceeds to model the proposed MPLSFP problem by using the stochastic programming approach. A solution method will be designed for solving the stochastic programming model developed in this study.

The contributions of this study are threefold: firstly, a realistic MPLSFP problem that can deal with container transshipment operations and stochastic dependency of the period-dependent uncertain container shipment demand is proposed. Secondly, a workable novel way for a liner container shipping company to make a multi-period liner ship fleet plan is put up. Thirdly, the proposed MPLSFP problem is formulated as a multi-period stochastic programming model comprising a series of interrelated stochastic programming models developed for each period in the multi-period planning horizon.

This remainder of this paper is organized as follows. Section 2 illustrates a ship route coding scheme and analyzes the stochastic dependency of the random period dependent container shipment demand and defines the MPLSFP problem Section 3 
elaborates the procedure for determining a liner ship fleet plan as a decision tree, and builds a multi-period stochastic programming model for the proposed MPLSFP problem. Section 4 designs a solution method for solving the multi-period stochastic programming model. Section 5 gives numerical experiments to illustrate the model and solution method. Conclusions are presented in Section 6.

\section{PROBLEM STATEMENT}

Consider a liner container shipping company operating a set of ship routes denoted by $\mathcal{R}=\{1, \ldots, r, \ldots, R\}$ serving a set of ports denoted by $\mathcal{P}=\{1, \ldots, p, \ldots P\}$, in a multi-period planning horizon $\mathcal{T}$ is divided into $T$ periods denoted by $\mathcal{T}=\{1, \ldots, t, \ldots, T\}$. Indices $R, P$ and $T$ are the number of liner ship routes, ports and periods, respectively, and $r, p$ and $t$ denote a specific ship route, port and single period, respectively. The length of one single period can be determined according to the changes in container shipment demand forecasted in the multi-period planning horizon; for example, one period could be one year. Each ship route $r \in \mathcal{R}$ can be expressed by the port calling sequence (or itinerary):

$$
p_{r}^{1} \rightarrow p_{r}^{2} \rightarrow \cdots \rightarrow p_{r}^{m_{r}} \rightarrow p_{r}^{1}
$$

where $p_{r}^{i} \in \mathcal{P}\left(i=1, \cdots, m_{r}\right)$ is the $i^{\text {th }}$ port of call on ship route $r$ and $m_{r}$ is the number of port calls on this route. The ship route coding scheme shown in Eq. (1) describes the unique characteristic of a liner shipping route: a loop with a given port calling order.

[Figure 1 is inserted here]

For example, Figure 1 depicts a liner shipping route between Pusan port and Singapore port. A ship serving this liner shipping route first calls at Pusan (PS) followed by Shanghai (SH), Yantian (YT), Hong Kong (HK), Singapore (SG), Yantian (YT), and 
finally returns to Pusan (PS). According to Eq. (1), it can be expressed by the port calling sequence:

$$
p_{r}^{1}(\mathrm{PS}) \rightarrow p_{r}^{2}(\mathrm{SH}) \rightarrow p_{r}^{3}(\mathrm{YT}) \rightarrow p_{r}^{4}(\mathrm{HK}) \rightarrow p_{r}^{5}(\mathrm{SG}) \rightarrow p_{r}^{6}(\mathrm{YT}) \rightarrow p_{r}^{1}(\mathrm{PS})(2)
$$

To facilitate formulation of the feature that the first port and last port called at on a given liner shipping route are the same, we define a generalized mod operator as follows:

$$
i \underline{\bmod } m_{r}= \begin{cases}i \bmod m_{r}, & i \neq m_{r} \\ m_{r}, & i=m_{r}\end{cases}
$$

The voyage from port $p_{r}^{i}$ to $p_{r}^{(i+1) \underline{\bmod } m_{r}}$ is called leg $i\left(i=1,2, \ldots, m_{r}-1\right)$ of the ship route $r \in \mathcal{R}$, denoted by the pair of ordered ports $\left\langle p_{r}^{i}, p_{r}^{(i+1) \underline{\bmod } m_{r}}>\right.$, and leg $m_{r}$ stands for the voyage from port call $p_{r}^{m_{r}}$ to port call $p_{r}^{1}$

\subsection{Container route with container transshipment operations}

Let $\mathcal{W}=\{(o, d) \mid o \in \mathcal{P}, d \in \mathcal{P}\}$ be the set of origin-to-destination (O-D) port pairs with container shipment demand. Given the set of ship routes $\mathcal{R}$, the liner container shipping company can predetermine a set of candidate container routes to transport containers between an O-D port pair $(o, d) \in \mathcal{W}$, denoted by the set $\mathcal{H}^{\text {od }}$. A container route $h^{\text {od }} \in \mathcal{H}^{\text {od }}$ is either a part of one particular ship route or a combination of several ship routes and delivers containers from the origin port $o \in \mathcal{P}$ to the destination port $d \in \mathcal{P}$.

\section{[Figure 2 is inserted here]}

For example, there are two possible container routes from Jakarta (JK) to Shanghai (SH) shown in Figure 2: 


$$
\begin{gathered}
h_{1}^{\mathrm{JK} \cdot \mathrm{SH}}=p_{1}^{1}(\mathrm{JK}) \stackrel{\text { Ship Route } 1}{\longrightarrow} p_{1}^{2}(\mathrm{SG}) \mapsto p_{3}^{2}(\mathrm{SG}) \stackrel{\text { Ship Route 3 }}{\longrightarrow} p_{3}^{3}(\mathrm{SH}) \\
h_{2}^{\mathrm{JK} \cdot \mathrm{SH}}=p_{2}^{1}(\mathrm{JK}) \stackrel{\text { Ship Route 2 }}{\longrightarrow} p_{2}^{2}(\mathrm{SH})
\end{gathered}
$$

The first container route $h_{1}^{\mathrm{JK} . \mathrm{SH}}$, makes up of with two ship routes and involves container transshipment operations: containers are loaded at the first port of call of ship route 1 (Jakarta) and delivered to the second port of call of ship route 3 (Singapore). At Singapore port, these containers are discharged and reloaded (transshipped) to a ship deployed on ship route 3, and transported to the destination port, Shanghai. However, the second container route $h_{1}^{\mathrm{JK} . \mathrm{SH}}$ provides a direct delivery service via ship route 2 , without container transshipment.

A container route contains all of the information on how containers are transported including origin, destination, ports of call along the route and any transshipment ports. An O-D port pair may be served by several container routes, thus containers between the O-D port pair could be split among these container routes. For the sake of presentation, let $\mathcal{H}$ be the set of all of the predetermined container routes for all of the O-D port pairs, namely,

$$
\mathcal{H}=\bigcup_{(o, d) \in \mathcal{W}} \mathcal{H}^{o d}
$$

\subsection{Stochastic dependency of period-dependent random container shipment demand}

Let $\xi_{t}^{o d}$ be the number of containers in terms of TEUs (twenty-foot equivalent units) to be transported between an O-D port pair $(o, d) \in \mathcal{W}$ in a particular single period $t \in \mathcal{T}$. The uncertainty of container shipment demand in the period $t \in \mathcal{T}$ is formulated by a set of discrete demand scenarios denoted by $\mathcal{S}_{t}=\left\{1, \ldots\right.$, s..., $\left.S_{t}\right\}$. For each 
scenario $s \in \mathcal{S}_{t}$, values for the container shipment demand between each port pair in period $t \in \mathcal{T}$ are specified. Associated with each scenario $s \in \mathcal{S}_{t}$ is a probability that the scenario could happen, denoted by $p_{s}^{t}$ satisfying $\sum_{s=1}^{S_{t}} p_{s}^{t}=1$. In other words, the container shipment demand between each port pair in a particular period, namely $\xi_{t}^{o d}((o, d) \in \mathcal{W}, t \in \mathcal{T})$, is assumed to be a discrete random variable taking a limited number of possible values with known occurrence probabilities.

It is reasonable to assume that the container shipment demand in period $t$ is only dependent on that in the previous period. Hence, the scenario $s \in \mathcal{S}_{t}$ is dependent on the scenario $s^{\prime} \in \mathcal{S}_{t-1}$. Let $p_{s \mid s^{\prime}}^{t}$ be the conditional probability that scenario $s$ occurs in period $t$ given that scenario $s^{\prime}$ happened in period $t-1, p_{s}^{t}$ can be calculated by:

$$
p_{s}^{t}=\sum_{s^{\prime}=1}^{S_{t-1}} p_{s^{\prime}}^{t-1} \times p_{s s^{\prime}}^{t}
$$

Since scenario $s \in \mathcal{S}_{t}$ occurs in period $t$ with conditional probability $p_{s \mid s^{\prime}}^{t}$, given that scenario $s^{\prime} \in \mathcal{S}_{t-1}$ occurs in period $t-1$, all the scenarios in the whole $T$-period planning horizon can be depicted as a scenario tree with $T$ layers, where each layer corresponds to a single period. Take the liner ship route shown in Figure 1 as an example. For simplicity, consider two periods (say two years) and three O-D pairs: PS $\rightarrow$ SH, SH $\rightarrow$ YT, and YT $\rightarrow$ HK. Suppose that there are three discrete scenarios of container shipment demand in each year: L (low), M (medium) and H (high), as shown in Table 1.

[Table 1 is inserted here]

[Figure 3 is inserted here] 
Figure 3 gives the scenario tree with two layers with respect to the scenarios for the two-year period. The value on each branch in the two-layer scenario tree is the probability or conditional probability of each scenario's occurrence. Accordingly, the probabilities of each of the three scenarios in year 2 are computed as follows:

$$
\begin{aligned}
& p_{H}^{2}=p_{H}^{1} \times p_{H \mid H}^{2}+p_{M}^{1} \times p_{H \mid M}^{2}+p_{L}^{1} \times p_{H \mid L}^{2}=0.7 \times 0.6+0.2 \times 0.5+0.1 \times 0.1=0.53 \\
& p_{M}^{2}=p_{H}^{1} \times p_{M \mid H}^{2}+p_{M}^{1} \times p_{M \mid M}^{2}+p_{L}^{1} \times p_{M \mid L}^{2}=0.7 \times 0.3+0.2 \times 0.3+0.1 \times 0.2=0.29 \\
& p_{L}^{2}=p_{H}^{1} \times p_{L \mid H}^{2}+p_{M}^{1} \times p_{L \mid M}^{2}+p_{L}^{1} \times p_{L \mid L}^{2}=0.7 \times 0.1+0.2 \times 0.2+0.1 \times 0.7=0.18
\end{aligned}
$$

\subsection{Fleet size and mix strategies}

The liner container shipping company can use its own ships to transport containers, and may also charter ships from ship chartering market or purchase new ships to meet its container shipment demand. The company may also charter out some of its own ships, depending on their capacity in terms of TEUs. A fleet size and mix strategy associated with a particular period within the $T$-period planning horizon is defined as a plan comprising the number of ships to be chartered, the number of the company's own ships to be chartered out, the number of its own ships to be used during the period and the number of new ships to be purchased. In practice, the liner container shipping company has to order new ships advanced from a shipyard because the shipyard has limited shipbuilding capacity and can only deliver a limited number of ships each year. To simplify the problem, we assume that ship delivery time is zero.

At the beginning of the period $t \in \mathcal{T}$, experts from the strategic development department of the liner container shipping company would propose several possible fleet size and mix strategies for the period, based on their experiences, and/or the available budget of the company for the period. It is thus assumed that there are a number of 
suggested fleet size and mix scenarios at the beginning of each period $t \in \mathcal{T}$. There is an inherent and implicit relation between these strategies from one period to the next. For example, assuming that the liner container shipping company currently owns three ships named by $\mathrm{A}, \mathrm{B}$ and $\mathrm{C}$, the experts might propose two possible fleet size and mix strategies at the beginning of period $t$. Strategy 1 might be to use the existing three ships, while strategy 2 might be to purchase a new ship D to use as well. These two strategies would lead to two different states of the ship fleet at the beginning of the next period $t+1$ : in the first state, there are three ships in the fleet, while in the second state there are four. Each of these two states becomes a possible initial state of the fleet at the beginning of period $t+1$. At the beginning of period $t+1$, the experts will propose a group of possible fleet size and mix strategies with respect to each of these two ship fleet states. This strategy decision process will be repeated until the end of the last period $T$, that is, the beginning of period $T+1$. The entire decision process of fleet size and mix strategies thus actually forms a decision tree containing $T$ layers.

\subsection{Multi-period liner ship fleet planning problem}

The MPLSFP problem with container transshipment and uncertain container shipment demand aims to maximize the total expected profit reaped over the whole $T$ period planning horizon by making an optimal joint ship fleet development and deployment plan. A joint fleet development and deployment plan consists of (i) a fleet size and mix strategy proposed by the experts at the beginning of each period (i.e., a fleet development plan), and (ii) a ship fleet deployment plan. A fleet deployment plan includes the allocation of the ships in the fleet to liner ship routes, the number of voyages by each ship on each liner shipping route $r \in \mathcal{R}$ required to maintain a given liner 
shipping service frequency on the route, and the number of lay-up days allocated to each ship for maintenance. The objective of the ship deployment plan is expected profit maximization under various scenarios of container shipment demand, for each of the given fleet size and mix strategies.

The rationale behind the adoption of this a period-by-period planning is that the liner container shipping company can flexibly adjust its ship fleet size and mix according to the varying container shipment demand in each period. As life time for a ship is limited life time, a ship fleet needs to be renewed when some old ships in the ship fleet reach their life time by purchasing or chartering in new ships. The adoption of period-byperiod planning thus also satisfies the physical requirement of the renewal of the fleet over time. We assume that the liner container shipping company makes its planning decisions at the beginning of each single period and this process is repeated until all the periods in the multi-period planning horizon have been covered. Therefore, the multiperiod ship fleet plan consists of a number of single-period ship fleet plans. At the end of the planning horizon, without loss of generality, we assume that all ships owned by the liner container shipping company are disposed of for their salvage values.

\section{MODEL DEVELOPMENT}

\subsection{Decision tree for the fleet development plan}

To determine a ship fleet development plan in a $T$-period planning horizon, we introduce a dummy node $O$ as the root of the decision tree to represent the current ship fleet state. That is, the decision tree grows from the root $O$. Each node in period $t$ $(t=1,2, \cdots, T-1)$ can be regarded as a parent and will generate some offspring in period $t+1$, that is, the fleet size and mix strategies for the next period. Each parent and its 
offspring are connected by an arc. It is noted that different parents may produce the same offspring. Each node of the decision tree, except the root, has a parent (which may not be unique). A parent $n$ at period $t$ and its offspring from period $t=1, \ldots, T-1$ to the end of the whole $T$-period planning horizon form a sub-tree, denoted by $\mathbb{T}^{t}(n)$. Each parent $n$, namely a non-terminal node in period $t=1, \ldots, T-1$, is the root of the sub-tree $\mathbb{T}^{t}(n)$. Thus $\mathbb{T}^{0}$ denotes the entire tree over the whole $T$-period planning horizon. The set of paths from root $O$ to a node $n$ in period $t$, is denoted by $\mathbb{P}^{t}(n)$ and each path $l \in \mathbb{P}^{t}(n)$ represents a development plan of fleet sizes and mixes for $t$ periods. If $n$ is a terminal node (i.e. a leaf), then path $l$ corresponds to a development plan for all $T$ periods.

[Figure 4 is inserted here]

Figure 4 schematically illustrates the decision tree. In Figure 4, let $\mathcal{N}_{t}=\left\{1, \ldots, N_{t}\right\}$ be the set of nodes in period $t \in \mathcal{T}$, where $N_{t}$ is the number of nodes in this set, and let $\mathcal{N}_{t}^{m}=\left\{1, \ldots, N_{t}^{m}\right\}$ be the set of strategies proposed for period $t+1$ which are generated from a particular strategy $m$ proposed for period $t$ where $N_{t}^{m}$ represents the number of strategies of the set $\mathcal{N}_{t}^{m}$. If each offspring node has a unique parent, we then have:

$$
\begin{gathered}
\mathcal{N}_{t+1}=\bigcup_{m \in \mathcal{N}_{t}} \mathcal{N}_{t}^{m}, t=1, \ldots, T-1 \\
N_{t+1}=\sum_{m=1}^{N_{t}} N_{t}^{m}, t=1, \ldots, T-1
\end{gathered}
$$

The following notation is used for the sake of presentation:

$\mathcal{G}_{t, n}^{\text {KEEP }}:$ set of company's own ships to be used at the beginning of period $t$ in strategy $n$ 
$\mathcal{G}_{t, n}^{\text {SOLD }}$ : set of company's own ships to be sold at the beginning of period $t$ in strategy $n$

$\mathcal{G}_{t, n}^{\text {OUT }}$ : set of own ships to be chartered out at the beginning of period $t$ in strategy $n$

$\mathcal{G}_{t, n}^{\mathrm{IN}}: \quad$ set of ships to be chartered in at the beginning of period $t$ in strategy $n$

$\mathcal{G}_{t, n}^{\mathrm{NEW}}$ : set of new ships bought at the beginning of period $t$ in strategy $n$

$\mathcal{G}_{t, n}$ : set of ships that are used to deliver containers at the beginning of period $t$ in strategy $n$

For a node (strategy) $n$ in period $t$, ships that can be used to deliver containers include the company's own ships, which are kept in service, new ships purchased at the beginning of period $t\left(\mathcal{G}_{t, n}^{\mathrm{NEW}}=\varnothing\right.$ if no available new ships $)$ and ships chartered in from ship chartering market. The set of ships used in strategy $n$ to deliver containers is given by:

$$
\mathcal{G}_{t, n}=\mathcal{G}_{t, n}^{\mathrm{KEEP}} \cup \mathcal{G}_{t, n}^{\mathrm{NEW}} \cup \mathcal{G}_{t, n}^{\mathrm{IN}}, \forall t \in \mathcal{T}
$$

The relationship between a parent $m$ in period $t$ and its offspring $n$ in period $t+1(t$ $=1, \ldots, T-1)$ is given by:

$$
\mathcal{G}_{t, m}^{\mathrm{KEEP}} \cup \mathcal{G}_{t, m}^{\mathrm{OUT}} \cup \mathcal{G}_{t, m}^{\mathrm{NEW}}=\mathcal{G}_{t+1, n}^{\mathrm{KEEP}} \cup \mathcal{G}_{t+1, n}^{\mathrm{OUT}} \cup \mathcal{G}_{t+1, n}^{\mathrm{SOLD}}, m=1, \ldots, N_{t}, n=1, \ldots, N_{t}^{m}, t=1, \ldots, T-1(12)
$$

\subsection{SSP models for the ship fleet deployment plans}

In Section 3.1, each node $n$ in period $t \in \mathcal{T}$ represents a fleet size and mix strategy proposed by the liner container shipping company's experts, based on their experience and the available budget (the budget is used for investment in the chartering in or purchase of new ships). However, the decisions of how to properly deploy the ships in the fleet, as given by the fleet size and mix strategy $n$ in period $t \in \mathcal{T}$, in order to 
maximize the profit gained from shipping containers over period $t$, have not yet been determined. Four types of decision variables are now defined as follows:

$\delta_{n t}^{k r}$ : binary variables equal to 1 if ship $k$ is assigned to route $r$ in strategy $n$ of period $t$ and 0 otherwise

$x_{n t}^{k r}: \quad$ number of voyages sailed by ship $k$ on route $r$ in strategy $n$ of period $t$

$y_{n t}^{k}: \quad$ number of lay-up days of ship $k$ in strategy $n$ of period $t$

$Z_{\text {snt }}^{h^{\text {od }}}: \quad$ number of containers carried by ships deployed on the container route $h^{\text {od }} \in \mathcal{H}^{\text {od }}$ between O-D port pair $(o, d) \in \mathcal{W}$ under container shipment demand scenario $s$ in strategy $n$ of period $t$

Given (i) the set of ships under strategy $n$ of period $t$, namely $\mathcal{G}_{t, n}$, (ii) the values of $\xi_{t}^{o d}$ for a port pair $(o, d) \in \mathcal{W}$ under scenario $s \in \mathcal{S}_{t}$ in period $t \in \mathcal{T}$, denoted by $\omega_{s t}^{o d}$, and (iii) the freight rate of transporting a container from its origin port $o$ to its destination port $d$ by container route $h$ in period $t(\$ / T E U)$, denoted by $f_{t}^{h^{o d}}$, the revenue gained from shipping containers along all possible routes in period $t$ under container shipment demand scenario $s$ is given by:

$$
\sum_{(o, d) \in \mathcal{W}} \sum_{h^{o d} \in \mathcal{H}^{o d}} f_{t}^{h^{o d}} z_{\text {snt }}^{h^{o d}}\left(\omega_{s t}^{o d}\right)
$$

Other revenue gained in strategy $n$ in the period $t$ includes earnings from chartering out the company's ships and the salvage value gained from selling its ships. This is given by the following:

$$
\sum_{k \in \mathcal{G}_{t, n}^{\mathrm{OUT}}} C_{k t}^{\mathrm{OUT}}+\sum_{k \in \mathcal{G}_{t, n}^{\mathrm{SOLD}}} C_{k t}^{\mathrm{SOLD}}
$$


where $c_{k t}^{\text {OUT }}$ is the amount received for chartering out a particular ship $k$ at the beginning of period $t(\$)$ and $c_{k t}^{\text {SOLD }}$ is the amount received for selling out a ship $k$ at the beginning of period $t(\$)$.

The total costs incurred in strategy $n$ of period $t$ usually consist of the following components: container handling costs, the voyage costs of the ships in the fleet that are transporting containers, the lay-up costs of those ships undergoing maintenance, the cost of chartering in ships from other liner container shipping companies and the capital investment of purchasing new ships. The container handling costs incurred along a container route include the container loading cost at the origin port, the container discharging cost at the destination port and the container transshipment cost at transshipment ports (if any). Different container routes between any given O-D port pair may result in different container handling costs. For example, the container route shown in Eq. (4) and that in Eq. (5) both involve the container loading costs at JK and container discharging costs at $\mathrm{SH}$, but the former incurs an additional transshipment cost at SG. Let $c_{t}^{h^{\text {od }}}(\$ /$ TEU) denote the container handling cost per TEU incurred on container route $h^{\text {od }} \in \mathcal{H}^{\text {od }}$ over the period $t$, then the total container handling cost can be calculated by the formula

$$
\sum_{(o, d) \in \mathcal{W}} \sum_{h^{o d} \in \mathcal{H}^{\text {od }}} C_{t}^{h^{o d}} Z_{\text {snt }}^{h^{o d}}\left(\omega_{s t}^{o d}\right)
$$

The voyage costs of the ships in the fleet that are used to transport containers, plus lay-up costs of those ships undergoing maintenance, plus the costs of chartering in ships from other liner container shipping companies and the capital investment of purchasing new ships is given by: 


$$
\sum_{r \in \mathcal{R}} \sum_{k \in \mathcal{G}_{t, n}} c_{k r t} x_{n t}^{k r}+\sum_{k \in \mathcal{G}_{t, n}} e_{k t} y_{n t}^{k}+\sum_{k \in G_{t, n}^{\mathrm{N}}} c_{k t}^{\mathrm{IN}}+\sum_{k \in \mathcal{G}_{t, n}^{\mathrm{NeW}}} c_{k t}^{\mathrm{NEW}}
$$

where $c_{k r t}$ is the voyage cost of operating a specific ship $k$ on route $r$ in period $t$ (\$/voyage), $e_{k t}$ is the daily lay-up cost for a specific ship $k$ in period $t(\$ /$ day $), c_{k t}^{\mathrm{NN}}$ is the cost of chartering in a specific ship $k$ at the beginning of period $t(\$), c_{k t}^{\mathrm{NEW}}$ is the price of the new ship $k$ at the beginning of period $t(\$)$.

As mentioned earlier, the fleet deployment plan of a specific fleet size and mix strategy $n$ in period $t$ is dependent on the container shipment demand of the previous period $t-1$. Therefore, given a fleet size and mix strategy $n$ in period $t$ which is produced by a parent $m$ of in period $t-1$, the optimal fleet deployment plan under this given strategy $n$ is dependent on the container shipment demand scenario $s^{\prime}$ over the previous period $t-1$, which can be formulated as a 2SSP model with the objective of maximizing the expected profit across all container shipment demand scenarios $s$ in period $t$, denoted by $E P_{t, n}^{m, s^{\prime}}$.

It is noted that the decision about $\delta_{n t}^{k r}, x_{n t}^{k r}$ and $y_{n t}^{k}$ are made prior to a realization of the random container shipment demand. In reality, the number of containers transported between an O-D port pair $(o, d) \in \mathcal{W}$ assigned to a particular container route can be determined only after the realization of the random container shipment demand. We can thus break down the set of all the decision variables into two stages. The firststage decision variables are $\delta_{n t}^{k r}, x_{n t}^{k r}$ and $y_{n t}^{k}$, and the second-stage variables are $z_{s n t}^{h^{\text {od }}}$. Therefore, the 2SSP model is as follows:

[2SSP] 


$$
\begin{aligned}
E P_{t, n}^{m, s^{\prime}}=\max & \sum_{k \in \mathcal{G}_{t, n}^{\mathrm{OUT}}} c_{k t}^{\mathrm{OUT}}+\sum_{k \in \mathcal{G}_{t, n}^{\mathrm{SOLD}}} c_{k t}^{\mathrm{SOLD}}-\sum_{r \in \mathcal{R}} \sum_{k \in \mathcal{G}_{t, n}} c_{k r t} x_{n t}^{k r}-\sum_{k \in \mathcal{G}_{t, n}} e_{k t} y_{n t}^{k}-\sum_{k \in \mathcal{G}_{t, n}^{\mathrm{IN}}} c_{k t}^{\mathrm{IN}}-\sum_{k \in \mathcal{G}_{t, n}^{\mathrm{NEW}}} c_{k t}^{\mathrm{NEW}} \\
& +\sum_{s \in \mathcal{S}_{t}} p_{s \mid s^{\prime}}^{t}, Q_{\xi}^{t s}(\mathbf{v}, \boldsymbol{\xi}(\boldsymbol{\omega}))
\end{aligned}
$$

subject to

$$
\begin{gathered}
\delta_{n t}^{k r} \leq x_{n t}^{k r} \leq M^{k r} \delta_{n t}^{k r}, \forall r \in \mathcal{R}, \forall k \in \mathcal{G}_{t, n} \\
\sum_{k \in \mathcal{G}_{t, n}} x_{n t}^{k r} \geq N_{t}^{r}, \forall r \in \mathcal{R} \\
\Delta t-T_{k}^{t} \leq y_{n t}^{k}, \forall k \in \mathcal{G}_{t, n} \\
x_{n t}^{k r} t^{k r}+y_{n t}^{k}=\Delta t, \forall r \in \mathcal{R}, \forall k \in \mathcal{G}_{t, n} \\
\sum_{r \in \mathcal{R}} \delta_{n t}^{k r}=1, \forall k \in \mathcal{G}_{t, n} \\
x_{n t}^{k r} \in \mathbb{Z}^{+} \bigcup\{0\}, \forall k \in \mathcal{G}_{t, n}, \forall r \in \mathcal{R} \\
y_{n t}^{k} \geq 0, \forall k \in \mathcal{G}_{t, n} \\
\delta_{n t}^{k r}=\{0,1\}, \forall k \in \mathcal{G}_{t, n}, \forall r \in \mathcal{R}
\end{gathered}
$$

where, for succinctness, $\mathbf{v}=\left(\cdots \delta_{n t}^{k r} \cdots x_{n t}^{k r} \cdots y_{n t}^{k} \cdots\right)$ contains all first-stage decision variables, $M^{k r}$ represents the maximum number of voyages ship $k$ can complete on route $r$ during period $t, N_{t}^{r}$ is the number of voyages required on route $r$ during period $t$ in order to maintain a given level of service frequency, $\Delta t$ is the duration of period $t$ (days), $T_{k}^{t}$ represents the shipping season for ship $k$ in period $t$ (days), referring to the number of days within the planning horizon excluding the time for maintenance, $t^{k r}$ is the voyage time of ship $k$ on route $r$ (days/voyage), includes sailing time on sea (related to distance and average sailing speed) and time spent for container loading and discharging at ports 
(related to port productivity and ship type). $\mathbb{Z}^{+}$is the set of positive integers. $Q_{\xi}^{t s}(\mathbf{v}, \xi(\boldsymbol{\omega}))$ is a function used for the following second-stage optimization problem, which depends on the first-stage decision variables and the realization of container shipment demand, $\boldsymbol{\omega}$, under scenario $s$. Its value is obtained by solving the following optimization problem:

$$
Q_{\xi}^{t s}(\mathbf{v}, \xi(\boldsymbol{\omega}))=\max \sum_{(o, d) \in \mathcal{W}} \sum_{h^{\text {od }} \in \mathcal{H}^{\text {od }}}\left(f_{t}^{h^{\text {od }}}-c_{t}^{h^{\text {od }}}\right) z_{s n t}^{h^{\text {od }}}\left(\omega_{s t}^{\text {od }}\right)
$$

subject to

$$
\begin{gathered}
\sum_{k \in \mathcal{G}_{t, n}} x_{n t}^{k r} V_{k} \geq \sum_{(o, d) \in \mathcal{W}} \sum_{h^{o d} \in \mathcal{H}^{o d}} \rho_{i r}^{h^{o d}} z_{s n t}^{h^{o d}}\left(\omega_{s t}^{o d}\right), \forall i=1, \cdots, m_{r}, \forall r \in \mathcal{R}, \forall s \in \mathcal{S}_{t} \\
u_{s t}^{o d} \leq \sum_{h^{(o, d)} \in \mathcal{H}^{(o, d)}} z_{\text {snt }}^{h^{o d}}\left(\omega_{s t}^{o d}\right) \leq \xi^{o d}\left(\omega_{s t}^{o d}\right), \forall(o, d) \in \mathcal{W}, \forall s \in \mathcal{S}_{t} \\
z_{s n t}^{h^{o d}} \geq 0, \forall(o, d) \in \mathcal{W}, \forall h^{o d} \in \mathcal{H}^{o d}, \forall s \in \mathcal{S}_{t}
\end{gathered}
$$

where $V_{k}$ is the capacity of a particular ship $k$ (TEUs), $\rho_{i r}^{h^{o d}}$ is a binary coefficient which equals 1 if a container route $h^{\text {od }} \in \mathcal{H}^{\text {od }}$ contains leg $i$ of route $r$ and otherwise equals 0 and $u_{s t}^{\text {od }}$ denotes the number of mandatory containers that have to be transported between an O-D port pair $(o, d) \in \mathcal{W}$ under scenario $s$ in period $t$.

Eq. (17) is the objective function of the 2SSP model. Constraints (18) apply the big- $M$ method to ensure that, if $\delta_{t n}^{k r}$ equals 0 , then $x_{t n}^{k r}$ equals 0 ; otherwise, if $\delta_{t n}^{k r}$ were equal to 1 then $x_{t n}^{k r}$ would be a positive integer. The value of $M^{k r}$ can be given by $M^{k r}=\left\lfloor\Delta t / t^{k r}\right\rfloor$, where $\lfloor a\rfloor$ denotes the maximum integer not greater than $a$. Eqs. (19) give the number of voyages required on route $r$ in order to maintain a given level of shipping frequency. For example, if a weekly liner shipping service is required on each 
liner ship route during a planning horizon of six months, then $N_{t}^{r}=26$. Eqs. (20) provides the minimum number of lay-up days for ship $k$ on route $r$. Constraints $(21)$ indicate that the total voyage time for ship $k$ on route $r$ (sailing on the sea) plus its lay-up time should not exceed one single period. Constraints (22) ensure that each ship only serves on one route. Constraints (23) impose non-negative integer values on the decision variables $x_{n t}^{k r}$ and constraints (24) require the decision variables $y_{n t}^{k}$ to be non-negative, respectively. Constraints (25) define the decision variables $\delta_{t n}^{k r}$ to be binary.

Eq. (26) is the objective function of the second-stage optimization problem. The left-hand sides of the constraints (27) are the total transportation capacity of ships deployed on the liner shipping route $r \in \mathcal{R}$. The right-hand sides are the total number of containers carried by ships sailing on leg $i$ of route $r \in \mathcal{R}$, including the containers loaded at previously calling ports which have remained on the ships plus any containers loaded or transshipped at port $p_{r}^{i}$. In other words, the constraints (27) ensure that the container flow on each leg carried on the ships does not exceed the ship capacity deployed on the route. The constraints (28) imply that the total number of containers assigned to all ship routes between an O-D port pair cannot exceed the corresponding container shipment demand. In practice, a liner container shipping company usually has contractual obligations with some shippers, meaning that a certain number of containers have to be shipped, while the rest are optional. The right-hand sides of constraints (28) are the realization of container shipment demand between an O-D port pair $(o, d) \in \mathcal{W}$ under scenario $s$. Therefore, the right-hand inequality of constraints (28) ensures that the number of containers carried on the ships does not exceed the demand, while the left- 
hand inequality guarantees that the mandatory containers are shipped. Constraints (29) require that the decision variables $z_{s n t}^{h^{o d}}$ should be non-negative. According to Eqs. (27)(28), it can be seen that container shipment demand between some pairs of ports may not fully fulfilled. For the sake of presentation, the penalty cost is not imposed on the unfulfilled container shipment although it is straightforward to add the penalty cost into the objective function in $\mathrm{Eq}(26)$.

After $E P_{t, n}^{m, s^{\prime}}$ is obtained by solving the 2SSP model above, we can then calculate the expected profit under strategy $n$ in period $t$ given strategy $m$ was applied in period $t-1$, which is denoted by $E P_{t, n}^{m}\left(t=1, \ldots, T ; n=1, \ldots, N_{t}\right)$, and given by:

$$
E P_{t, n}^{m}=\sum_{s^{\prime} \in \mathcal{S}_{t-1}} p_{s^{\prime}}^{t-1} \times E P_{t, n}^{m, s^{\prime}}
$$

\subsection{Multi-period stochastic programming model for the MPLSFP problem}

At the end of period $T$, the set of ships owned by the liner container shipping company under strategy $n^{\circ}$, denoted by $\overline{\mathcal{G}}_{T, n^{\circ}}$, includes ships that were kept, ships that were chartered out and ships that were bought at the beginning of period $T$ :

$$
\overline{\mathcal{G}}_{T, n^{\circ}}=\mathcal{G}_{T, n^{\circ}}^{\mathrm{KEEP}} \cup \mathcal{G}_{T, n^{\circ}}^{\mathrm{OUT}} \cup \mathcal{G}_{T, n^{\circ}}^{\mathrm{NEW}}, n^{\circ}=1, \ldots, N_{T}
$$

All ships owned by the liner container shipping company are disposed of at the end of period $T$ for their salvage values, which is denoted by $S V_{T, n^{\circ}}$. The objective of the MPLSFP problem is to find the best policy that maximizes the sum of the expected profits across the whole $T$-period planning horizon plus the salvage value. Here a policy refers to a path from the dummy root $O$ to the leaf node $n^{\circ} \in \mathcal{N}_{T}=\left\{1, \ldots, N_{T}\right\}$ in the decision tree. Therefore, the best policy refers to the path from the dummy root $O$ to a 
leaf node $n^{\circ}$ in the decision tree, with the maximal sum of expected profits plus salvage values. The length of a path is, as usual, the sum of the length of the arcs that it contains.

Let $\mathcal{L}_{t, n}^{n^{\circ}, l}$ be 1 if a path $l \in \mathbb{P}^{T}\left(n^{\circ}\right)$ from the dummy root $O$ to the leaf node $n^{\circ}$ passes node $n$ of period $t$, and 0 otherwise $\left(n^{\circ}=1, \ldots, N_{\mathrm{T}}\right)$. The best path, with the maximal sum of expected profits across all period plus salvage value, that is, the optimal plan for the MPLSFP problem, is given by:

$$
Z=\max _{\substack{l \in \mathbb{P}^{T}\left(n^{\circ}\right) \\ n^{\circ} \in \mathcal{N}_{T}}} \sum_{n, m \in \mathbb{T}^{0}} \sum_{t=1}^{T} \frac{E P_{t, n}^{m} \mathcal{L}_{t, n}^{n^{\circ}, l}}{(1+r)^{t}}+\frac{S V_{T, n^{\circ}}}{(1+r)^{T}}
$$

where $r$ is the discount rate for each period during the multi-period planning horizon.

\section{SOLUTION METHOD}

As shown in Figure 5, the expected profit on each arc contributes to the total profit along a given path from the dummy root $O$ to a leaf node $n^{\circ}$. In order to find the path with the greatest total profits across all periods, the attribute of each arc, $E P_{t, n}^{m}$, and the salvage value $S V_{T, n^{\circ}}$ have to be obtained. Once each $E P_{t, n}^{m}$ is obtained, the path from the dummy root $O$ to a leaf node $n^{\circ}$ with the maximal total profit can be found. Therefore, the key aspect of the solution method is to obtain $E P_{t, n}^{m}$, that is to solve the 2SSP model. The following firstly proposes a solution method to deal with the 2SSP model in order to get $E P_{t, n}^{m}$, and then describes an algorithm for finding the best path for the proposed MPLSFP problem in this paper.

[Figure 5 is inserted here]

\subsection{Dual decomposition and Lagrangian relaxation method}


It is noted that each 2SSP model under strategy $n$ for period $t$ involves a number of scenarios of the uncertain container shipment demand. Even when the first-stage decisions are given and fixed, $S_{t}(t=1, \ldots, T)$ optimization models (26) have to be solved in order to obtain the expected value associated with this given set of fixed first-stage decisions

In order to effectively solve a 2SSP model under strategy $n$ for period $t$ ( $n=$ $\left.1, \ldots, N_{t} ; t=1, \ldots, T\right)$, the dual decomposition and Lagrangian relaxation method proposed by [31] is used because it can decompose the 2SSP model into $S_{t}$ sub-problems based on the scenarios of container shipment demand. In order to do that, the first-stage variables are copied for each scenario. Such duplication might result in a new problem: the firststage decision variables $\mathbf{v}_{s}$ for each scenario $s\left(s=1, \ldots, S_{t}\right)$ could be different. However, the first-stage decision variable vector $\mathbf{v}_{s}\left(s=1, \ldots, S_{t}\right)$ in the 2SSP model should be independent of uncertain container shipment demand because they are made prior to knowing the exact market demand. Therefore, the non-anticipativity constraints $\mathbf{v}_{1}=\mathbf{v}_{2}=\cdots=\mathbf{v}_{S_{t}}(t=1, \cdots, T)$ are added, to guarantee that the first-stage decisions in period $t$ do not depend on the scenarios. The non-anticipativity constraints are implemented through the equation $\sum_{s \in \mathcal{S}_{t}} \mathbf{H}^{s} \mathbf{v}^{s}=\mathbf{0}(t=1, \ldots, T)$ where $\mathbf{H}^{s}$ is a suitable matrix with $\left(S_{t}-1\right) \times\left(2 K_{t n} R+K_{t n}\right)$ rows and $2 K_{t n} R+K_{t n}$ columns ( $K_{t n}$ is the cardinality of set $\mathcal{G}_{t, n}$, namely the number of ships; $2 K_{t n} R+K_{t n}$ is the number of first-stage decision variables $x_{n t}^{k r}, y_{n t}^{k}$ and $\delta_{n t}^{k r}$ ) for $s=1, \ldots, S_{t}$ defined as follows: 


$$
\begin{aligned}
& \mathbf{H}^{1}=(\mathbf{I}, \mathbf{0}, \cdots, \mathbf{0})^{\prime}, \mathbf{H}^{2}=(-\mathbf{I}, \mathbf{I}, \mathbf{0}, \cdots \mathbf{0})^{\prime}, \mathbf{H}^{3}=(\mathbf{0},-\mathbf{I}, \mathbf{I}, \cdots \mathbf{0})^{\prime}, \cdots, \\
& \mathbf{H}^{S_{t}-1}=(\mathbf{0}, \cdots,-\mathbf{I}, \mathbf{I})^{\prime}, \mathbf{H}^{S_{t}}=(\mathbf{0}, \cdots \mathbf{0},-\mathbf{I})^{\prime}
\end{aligned}
$$

where $\mathbf{I}$ and $\mathbf{0}$ are the square unity matrix and zero matrix of size $2 K_{t n} R+K_{t n}$, respectively.

Let $\lambda$ be a $\left(S_{t}-1\right) \times\left(2 K_{t n} R+K_{t n}\right)$-dimensional vector of Lagrangian multiplier associated with the non-anticipativity constraints. The resulting Lagrangian relaxation is as follows:

\section{$\left[\mathbf{L R}_{\mathbf{t}, \mathrm{n}}\right]$}

$$
L R_{t, n}(\lambda)=\max \sum_{s \in \mathcal{S}_{t}} p_{s \mid s^{\prime}}^{t}\left(\begin{array}{l}
\sum_{k \in \mathcal{G}_{t, n}^{\mathrm{UUT}}} c_{k t}^{\mathrm{OUT}}+\sum_{k \in \mathcal{G}_{t, n}^{\mathrm{SOLD}}} c_{k t}^{\mathrm{SOLD}}-\sum_{k \in \mathcal{G}_{t, n}^{\mathrm{N}, n}} c_{k t}^{\mathrm{IN}}-\sum_{k \in \mathcal{G}_{t, n}^{\mathrm{NeW}}} c_{k t}^{\mathrm{NEW}} \\
-\sum_{r \in \mathcal{R}} \sum_{k \in \mathcal{G}_{t, n}} c_{k r t} x_{n t}^{k r s}-\sum_{k \in \mathcal{G}_{t, n}} e_{k t} y_{n t}^{k s}+Q_{\xi}^{t s}\left(\mathbf{v}^{s}, \xi(\boldsymbol{\omega})\right)
\end{array}\right)+\lambda^{\prime} \mathbf{H}^{s} \mathbf{v}^{s}
$$

subject to constraints (18)-(24) and (27)-(29) for each scenario of container shipment demand. This Lagrangian relaxation model $\mathbf{L R}_{\mathbf{t}, \mathbf{n}}$ can be further decomposed into $S_{t}$ separate mixed-integer linear programming problems according to the $S_{t}$ container shipment demand scenarios, namely:

$$
L R_{t, n}(\lambda)=\sum_{s \in \mathcal{S}_{t}} L R_{t, n}^{s}(\lambda)
$$

where

$$
L R_{t, n}^{s}(\boldsymbol{\lambda})=\max p_{s \mid s^{\prime}}^{t}\left(\begin{array}{l}
\sum_{k \in \mathcal{G}_{t, n}^{\mathrm{OUT}}} c_{k t}^{\mathrm{OUT}}+\sum_{k \in \mathcal{G}_{t, n}^{\mathrm{SOLD}}} c_{k t}^{\mathrm{SOLD}}-\sum_{k \in \mathcal{G}_{t, n}^{\mathrm{IN}}} c_{k t}^{\mathrm{NN}}-\sum_{k \in \mathcal{G}_{t, n}^{\mathrm{NEW}}} c_{k t}^{\mathrm{NEW}} \\
-\sum_{r \in \mathcal{R}} \sum_{k \in \mathcal{G}_{t, n}} c_{k r t} x_{n t}^{k r s}-\sum_{k \in \mathcal{G}_{t, n}} e_{k t} y_{n t}^{k s}+Q_{\xi}^{t s}\left(\mathbf{v}^{s}, \xi(\boldsymbol{\omega})\right)
\end{array}\right)+\boldsymbol{\lambda}^{\prime} \mathbf{H}^{s} \mathbf{v}^{s}
$$

subject to constraints (18)-(24) and (27)-(29) associated with the $s^{\text {th }}$ scenario of container shipment demand.

Each subproblem shown in Eq. (36) can be solved efficiently using an optimization solver such as CPLEX for solving the integer linear integer programming 
broblems. It is straightforward to demonstrate that $L R_{t, n}(\lambda)$, the objective function value of the $\mathbf{L R}_{\mathbf{t}, \mathbf{n}}$ model with respect to a given Lagrangian multiplier $\boldsymbol{\lambda}$, is an upper bound on the optimal value of Eq.(17). The best or tightest upper bound is found by solving the Lagrangian dual:

$$
\left[\mathbf{L D}_{\mathbf{t}, \mathbf{n}}\right] \quad L D_{t, n}=\min _{\lambda} L R_{t, n}(\boldsymbol{\lambda})
$$

which is solved by the subgradient method, a brazen adaptation of the gradient method in which gradients are replaced by subgradients. It shown that $\sum_{s \in \mathcal{S}_{t}} \mathbf{H}^{s} \mathbf{v}^{s^{*}}$ is the subgradient of (34) where $\mathbf{v}^{s^{*}}$ is the optimal solution of the $s^{\text {th }}$ subproblem (36) (Carøe and Schultz, 1999). With this subgradient, the $\mathbf{L R}_{\mathbf{t}, \mathbf{n}}$ model can be solved using the following subgradient method:

Step 0: Give an initial Lagrangian multiplier vector $\lambda^{(1)}$. Let the number of iterations $h=1$.

Step 1: Calculate the subgradient $\sum_{s \in \mathcal{S}_{t}} \mathbf{H}^{s} \mathbf{v}^{s^{*}(h)}$ by solving the subproblem shown in Eq. (36) with respect to the Lagrangian multiplier vector $\lambda^{(h)}$.

Step 2: Update the Lagrangian multiplier vector according to the formula:

$$
\lambda^{h+1}=\lambda^{h}+\alpha^{h} \sum_{s \in \mathcal{S}_{t}} \mathbf{H}^{s} \mathbf{v}^{s^{*}(h)}
$$

where $\alpha^{h}$ is a positive scalar step size, and given by the following formula (Fisher, 1981):

$$
\alpha^{h}=1 / h
$$


Step 3: If the following criterion is fulfilled, the algorithm is terminated. Otherwise, let $h=h+1$ and go to Step 1 .

$$
\left|\left(L R_{t, n}\left(\lambda^{h+1}\right)-L R_{t, n}\left(\lambda^{h}\right)\right) / L R_{t, n}\left(\lambda^{h}\right)\right| \leq \tau
$$

where $\tau$ is a given threshold value.

It is noted that the global convergence of this subgradient method has been proved in (Pojak, 1967), namely $L R_{t, n}\left(\lambda^{h}\right) \rightarrow L D_{t, n}$, if $\alpha^{h} \rightarrow 0$ and $\sum_{h=0}^{\infty} \alpha^{h} \rightarrow \infty$. Obviously, the step size adopted in this study fulfills the condition. Therefore, the dual decomposition method proposed in this study is theoretically convergent.

\subsection{Longest path algorithm for the MPLSFP problem}

Once the attribute of each arc has been obtained using the solution method described in Section 4.1, the next step is to find the longest path from the dummy root $O$ to a leaf node, with the maximal profit (summed across all arcs contained in this path) plus salvage value. Each leaf node, $n^{\circ}$, is connected to a dummy destination node, $D$ (shown in Figure 5), by a dummy arc, and the value on each dummy arc is set equal to the salvage value of this leaf node, $S V_{T, n^{\circ}}$. Then, finding the longest path from the dummy root $O$ to a leaf node is equivalent to finding the longest path from $O$ to $D$ in the acyclic network shown in figure 5. A few shortest path algorithms (Ahuja, Magnanti, and Orlin, 1996) can be used for solving the longest path problem. It is noted that, theoretically, it is possible that there is no feasible solution when solving the 2SSIP model (26). For this case, we just set $E P_{t, n}^{m, s^{\prime}}=-\infty$

\section{COMPUTATIONAL EXPERIMENTS}

\subsection{A numerical example design}


In order to illustrate applicability of the proposed approach for solving the MPLSFP problem with container transshipment and demand uncertainty, we assume that the liner container shipping company intends to make a 10 -year liner ship fleet plan for eight ship routes shown in Figure 6. Note that these ship routes are now operated by the liner container shipping company OOCL in Hong Kong. These eight ship routes involve a total of 36 ports of call, 390 O-D pairs and 443 container routes.

[Figure 6 is inserted here]

The ports called at on each liner shipping route and their digital number codes are shown in Table 2. Table 3 gives the distances of each leg on each ship route. The relevant ship data are presented in Table 4, including ship size and type, daily operating and layup costs, annual chartering in and out rates, selling and purchasing prices. The initial ship fleet consists of 27 ships, including two ships of type 1, two ships of type 2 , nine ships of type 3, two ships of type 4 and twelve ships of type 5.To simplify the input data preparation, it is assumed that these cost parameters do not change within the time horizon. The daily operating costs of each ship type are estimated using the following regression equation in (Shintani et al., 2007) since the exact data are unavailable:

$$
\text { daily operating cost }=6.54 \times \text { ship size }+1422.5(\$)
$$

[Table 2 is inserted here]

[Table 3 is inserted here]

[Table 4 is inserted here]

\subsection{Generation of demand scenarios and fleet size and mix strategies}

We assume there are three scenarios of container shipment demand high, medium and low in each single period (i.e. one year), with associated probabilities of $0.35,0.40$ and 0.25 , as shown in Figure 7, and the container shipment demand increases at an annual 
rate of 8000,5000 and 2000 TEUs for each scenario, respectively. Additionally, we assume three feasible strategies shown in Table 5 are proposed by the liner container shipping company's experts at the beginning of each year. A strategy involves five options: keep, charter out, sell, charter in and buy ships. We use five capital letters: $K, O$, $S, I$ and $B$ to represent those five options, respectively. Additionally, the superscript and the subscript of the capital letters in a strategy represent the ship type and the number of ships of this type, respectively. For example, the strategy $K_{2}^{1} K_{2}^{2} K_{9}^{3} I_{1}^{3} K_{2}^{4} K_{12}^{5}$ in year 1 indicates that a total of 28 ship are contained in the ship fleet, of which two ships of type 1 , two ships of type 2 , nine ships of type 3 , two ships of type 4 and twelve ships of type 5 are kept in the ship fleet and one ship of type 3 is chartered in.

[Figure 7 is inserted here]

[Table 5 is inserted here]

\subsection{Profit comparison}

The results of the numerical example are illustrated as an acyclic network representation. It is found that the longest path from $O$ to $D$ is $O \rightarrow 1 \rightarrow 3 \rightarrow 3 \rightarrow 1 \rightarrow 1 \rightarrow 2 \rightarrow 2 \rightarrow 2 \rightarrow 2 \rightarrow 3 \rightarrow D$ with total profits of 95.2586 billion dollars.

As mentioned in Section 1.2, the most significant contribution of this study is to take the dependency of uncertain container shipment demand between periods into account in the MPLSFP problem. In order to assess impact of container shipment demand dependency on the profit, we calculate the total profit over the whole multi-period planning horizon, with the assumption that the container shipment demand in each period is independent of that in other periods, and compare the results with those produced 
above. For the sake of presentation, the case with dependency of container shipment demand is called case I hereafter (i.e. the problem studied in this paper) while the case with independent container shipment demand is called case II .

$$
\begin{aligned}
& \text { In case II, } E P_{t, n}^{m}\left(t=1, \ldots, T ; n=1, \ldots, N_{t}\right) \text { is given by: } \\
& \qquad P_{t, n}^{m}=\max \sum_{k \in \mathcal{G}_{t, n}^{\mathrm{OUT}}} c_{k t}^{\mathrm{OUT}}+\sum_{k \in \mathcal{G}_{t, n}^{\mathrm{SOLD}}} c_{k t}^{\mathrm{SOLD}}-\sum_{r \in \mathcal{R}} \sum_{k \in \mathcal{G}_{t, n}} c_{k r t} x_{n t}^{k r}-\sum_{k \in \mathcal{G}_{t, n}} e_{k t} y_{n t}^{k}-\sum_{k \in \mathcal{G}_{t, n}^{\mathrm{IN}}} c_{k t}^{\mathrm{IN}}-\sum_{k \in \mathcal{G}_{t, n}^{\mathrm{NEW}}} c_{k t}^{\mathrm{NEW}} \\
& +\sum_{s \in \mathcal{S}_{t}} p_{s}^{t} Q_{\xi}^{\mathrm{St}}(\mathbf{v}, \xi(\boldsymbol{\omega}))
\end{aligned}
$$

subject to constraints (18) to (29).

We found that the total profit in case II was 95.0217 billion dollars, which is lower than those in case I. This indicates that the dependency of container shipment demand has a significant effect on profits and verifies that the importance of considering dependency between the container shipment demand in different periods. Actually, we have also theoretically proven that the profit in case II will be less than or equal to that in case I (see appendix).

\subsection{Comparison of fleet deployment plans}

This section investigates the effect of the dependency on the resulting fleet deployment plans. The 2SSP model (17) indicates that the fleet deployment plan under a given fleet strategy $n$ in period $t$ is dependent on the container shipment demand scenario $s^{\prime}$ of the previous period $t-1$. Since there are $S_{t-1}$ container shipment demand scenarios in period $t-1$, it is possible that there are $S_{t-1}$ different fleet deployment plans for a strategy $n$ in year $t(t=2, \ldots, T)$, where each fleet deployment plan corresponds to a container shipment demand scenario $s^{\prime}$ from the previous period $t-1$ and is obtained by solving the 
2SSP model (17). This shows that, in case I, the fleet deployment decisions for period $t$ take the container shipment demand from the previous period into account, and therefore, the fleet deployment plans are demand-dependent. In case II, the container shipment demand between periods is assumed to be independent, that is the container shipment demand in period $t-1$ is not taken into consideration in the fleet deployment plan developed for period $t$, which indicates that the fleet deployment plans are demandindependent. The optimization model (42) shows that, in case II, a strategy $n$ in year $t(t$ $=2, \ldots, T)$ has only one fleet deployment plan, which is obtained by solving the optimization model. Evidently, the demand-dependent fleet deployment plans in case I are more reasonable and flexible because the consideration of container shipment demand dependency in this case means that the liner container shipping company can adopt a proper fleet deployment plan based on the container shipment demand that came about in the previous period; in case II, meanwhile, the same fleet deployment plan must be adopted regardless of the scenario of container shipment demand that materialized in the previous year.

In the numerical example, each fleet strategy has three fleet deployment plans corresponding to three scenarios of demand: high, medium and low. For example, for the strategy $K_{2}^{1} K_{2}^{2} K_{9}^{3} I_{5}^{3} K_{2}^{4} K_{12}^{5}$ of year 2 in case $I$, three fleet deployment plans are shown in table 6. The fleet deployment plan for the same strategy in case II is shown in table 7. It is found that those fleet deployment plans are different; the reason for this is that the probabilities involved in the optimization models are different.

[Table 6 is inserted here] 
[Table 7 is inserted here]

\section{CONCLUSIONS AND FUTURE WORK}

This paper proposes a MPLSFP problem with container transshipment and uncertain container shipment demand. The uncertain container shipment demand in each period is assumed to be dependent on that of the previous period. A set of scenarios in each single period is used to reflect the uncertainty of container shipment demand, and then the evolution and dependency of container shipment demand across multiple periods is modeled as a scenario tree. A decision tree is used to interpret the procedure of fleet development over the multi-period planning horizon. The proposed MPLSFP problem is formulated as a multi-period stochastic programming model comprising a sequence of interrelated 2SSP models. In order to solve this model, the dual decomposition and Lagrangian relaxation method is employed to solve the 2SSP models; and then the solution to the MPLSFP problem is found by using the longest path algorithm on an acyalic network. Numerical experiments are carried out to evaluate the applicability and performance of model and solution method proposed in this study. Impact analysis of container shipment demand dependency is also examined. The results show that the profit obtained when considering dependency is higher and the ship fleet plans are more flexible than when dependency is not considered.

It is worth highlighting that the most significant contribution of this study is that it takes the first step towards a more realistic MPLSFP problem than has been studied in previous literature and provides an applicable and feasible method for handling such a problem in practice. It has to be pointed out that in this study the feasible fleet size and mix strategies in each single period are assumed to be proposed by experts in the liner 
container shipping company, rather than being regarded as decision variables. The rationale behind such an assumption is that it effectively reduces the searching space from the viewpoint of operations research and makes the MPLSFP problem solvable in practice; otherwise, the MPLSFP problem would be highly intractable. We also need to reduce the runtime further because the convergent rate of the harmonic series, i.e. the step size sequence $\left\{\alpha^{h}=1 / h, h=1,2,3, \ldots\right\}$ adopted in the solution algorithm, is inefficient. It might be worhwhile investigating whether a more sophisticated heuristic for finding feasible solutions would produce even better results.

Currently, only the expected profit is studied, and no attempt is made to control the variance (that is the risk that results from the uncertain environment). This will be a subject of our future research work. As the proposed problem is for strategic long-term planning horizon, it is reasonable to exclude the operational-level issue of demand peak seasonality. In further research, the demand peak seasonality at the operational level will be studied.

\section{ACKNOWLEDGEMENTS}

The authors appreciate to the editor and two anonymous reviewers for their valuable comments. This study is supported by the research grant with WBS No. R-302-000-014720 and WBS No. R-702-000-007-720 from the Neptune Orient Lines (NOL) Fellowship Programme of Singapore and supported by the research grant with No. 71201088 from the National Natural Science Funding of China.

\section{REFERENCES}

Agarwal, R. and Ergun, Ö., 2008. Ship scheduling and network design for container routing in liner shipping, Transportation Science, 42 (2), 175-196. 
Ahmed, S. and Sahinidis, N.V., 2003. An approximation scheme for stochastic integer programs arising in capacity expansion, Operations Research, 51 (3), 461-471.

Ahuja, R.A., Magnanti, T.L., Orlin, J.B., 1996. Network flows: Theory, Algorithms and Applications. Prentice Hall, New Jersey.

Carøe C.C. and Schultz R., 1999. Dual decomposition in stochastic integer programming. Operations Research Letter, 24, 37-45.

Celikyurt, U. and Özekici, S., 2007. Multiperiod portfolio optimization models in stochastic markets using the mean-variance approach, European Journal of Operational Research, 179, 186-202.

Cheaitou, A., Cariouz, P., 2012. Liner shipping service optimization with reefer containers capacity: an application to northern European-South America trade, Maritime Policy and Management, 39(6), 589-602.

Cho, S.C., Perakis, A.N., 1996. Optimal liner fleet routeing strategies, Maritime Policy and Management, 23(3), 249-259.

Christiansen, M., Fagerholt, K., Nygreen, B., Ronen, D., 2007. Maritime transportation. In: Barnhart, C. and Laporte, G. (Eds.), Handbook in OR \& MS, Volume 14. Elsevier, $189-284$

Christiansen, M., Fagerholt, K., Ronen, D., 2004. Ship routing and scheduling: status and perspectives. Transportation Science, 38(1), 1-18.

Cullinance, K. and Khanna, M., 1999. Economies of scale in large container ships. Journal of Transport Economics and Policy, 33(2), 185-207.

Dong, J.X. and Song, D.P., 2009. Container fleet sizing and empty repositioning in liner shipping systems, Transportation Research Part E, 45(6), 860-877. 
Fisher, M.L., 1981. The Lagrangian relaxation method for solving integer programming problems. Management Science, 1 (27), 1-18.

Gülpinar, N. and Rustem, B., 2007. Worst-case robust decisions for multi-period meanvariance portfolio optimization, European Journal of Operational Research, 183, 981-1000.

Jaramillo, D. I. and Perakis, A.N., 1991. Fleet deployment optimization for liner shipping Part 2. Implementation and results. Maritime Policy and Management, 18 (3), 235262.

Leung, S.C.H., Tsang, S.O.S., Ng., W.L. and Wu, Y., 2007. A robust optimization model for multi-site production planning problem in an uncertain environment, European Journal of Operational Research, 181, 224-238.

Listes, O. and Dekker, R., 2005. A scenario aggregation-based approach for determining a robust airline fleet composition for dynamic capacity allocation, Transportation Science, 39 (3), 367-382.

Meng, Q. and Wang, S., 2012. Liner ship fleet deployment with week-dependent container shipment demand, European Journal of Operational Research, 222(2), $241-252$

Meng, Q. and Wang, T., 2010. A chance constrained programming model for short-term liner ship fleet planning problems. Maritime Policy and Management, 37 (4), 329346.

Meng, Q. and Wang, T., 2011. A scenario-based dynamic programming model for multiperiod liner ship fleet planning. Transportation Research Part E, 47 (4), 401-413.

Meng, Q., Wang, T. and Wang, S., 2012. Short-term liner ship fleet planning with 
container transshipment and uncertain demand, European Journal of Operational Research, 223(1), 96-105.

Mourão, M.C., Pato, M.V. and Paixão, A.C., 2001. Ship assignment with hub and spoke constraints. Maritime Policy and Management, 29 (2), 135-150.

Nicholson, T.A.J. and Pullen, R.D., 1971. Dynamic programming applied to ship fleet management. Operational Research Quarterly, 22 (3), 211-220.

Perakis, A.N. and Jaramillo D. I., 1991. Fleet deployment optimization for liner shipping Part 1. Background, problem formulation and solution approaches. Maritime Policy and Management, 18 (3), 183-200.

Pojak, B.T., 1967. A general method of solving extreme problems. Soviet Mathematics Doklady, 8, 593-597.

Powell, B.J. and Perakis, A.N., 1997. Fleet deployment optimization for liner shipping: an integer programming model. Maritime Policy and Management, 24 (2), 183-192.

Ronen, D., 1983. Cargo ships routing and scheduling: Survey of models and problems. European Journal of Operational Research, 12, 119-126.

Ronen, D., 1993. Ship scheduling: The last decade. European Journal of Operational Research, 71, 325-333.

Shapiro, A. and Philpott, A., 2007. A tutorial on stochastic programming. http://www2.isye.gatech.edu/people/faculty/Alex_Shapiro/TutorialSP.pdf.

Shintani, K., Imai, A., Nishimura, E., Papadimitriou, S., 2007. The container shipping network design problem with empty container repositioning. Transportation Research Part E, 43 (1), 39-59.

Song, D.P., Zhang, J., Carter, J., Field, T., Marshall, M., Polak, J., Schumacher, K., Sinha- 
Ray, P., and Woods, J., 2005. On cost-efficiency of the global container shipping network, Maritime Policy \& Management, 32 (1), 15-30.

Vernimmen, B., Dullaert, W. and Engelen, S., 2007. Schedule unreliability in liner shipping: origins and consequences for the hinterland supply chain. Maritime Economics and Logistics, 9, 193-213.

Wang, S. and Meng, Q., 2012. Liner ship fleet deployment with container transshipment operations. Transportation Research Part E, 48 (2), 470-484.

Wang, S., Wang, T. and Meng, Q., 2011. A note on liner ship fleet deployment. Flexible Services and Manufacturing Journal, 23(4), 422-430.

Xie, X.L., Wang, T.F., Chen, D.S., 2000. A dynamic model and algorithm for fleet planning, Maritime Policy and Management, 27, 53-63. 


\section{APPENDIX}

In case $\mathrm{I}, E P_{t, n}^{m}$ is given by:

$$
E P_{t, n}^{m}=\sum_{s^{\prime} \in \mathcal{S}_{t-1}} p_{s^{\prime}}^{t-1} \times E P_{t, n}^{m, s^{\prime}}
$$

In Eq. (17), the terms $\sum_{k \in \mathcal{G}_{t, n}^{\text {OUT }}} C_{k t}^{\text {OUT }}, \sum_{k \in \mathcal{G}_{t, n}^{\text {Sold }}} C_{k t}^{\text {SOLD }}, \sum_{k \in \mathcal{G}_{t, n}^{\text {IN }}} c_{k t}^{\mathrm{IN}}$ and $\sum_{k \in \mathcal{G}_{t, n}^{\mathrm{NEW}}} C_{k t}^{\mathrm{NEW}}$ can be removed since they are fixed when the sets of $\mathcal{G}_{t, n}^{\mathrm{OUT}}, \mathcal{G}_{t, n}^{\mathrm{SOLD}}, \mathcal{G}_{t, n}^{\mathrm{IN}}$ and $\mathcal{G}_{t, n}^{\mathrm{NEW}}$ are given. Then Eq. (A-1) can be rewritten as follows after using Eq. (17) to replace $E P_{t, n}^{m, s^{\prime}}$ :

$$
\begin{aligned}
& E P_{t, n}^{m} \\
& =\sum_{s^{\prime} \in \mathcal{S}_{t-1}} p_{s^{\prime}}^{t-1} \times \max \left(\sum_{s \in \mathcal{S}_{t}} p_{s s^{\prime}}^{t} Q_{\xi}^{t s}(\mathbf{v}, \xi(\boldsymbol{\omega}))-\sum_{r \in \mathcal{R}} \sum_{k \in \mathcal{G}_{t, n}}\left(c_{k t}^{r} x_{n t}^{k r}+e_{k t} y_{n t}^{k}\right)\right) \\
& =\sum_{s^{\prime} \in \mathcal{S}_{t-1}} \max p_{s^{\prime}}^{t-1} \times\left(\sum_{s \in \mathcal{S}_{t}} p_{s s^{\prime}}^{t} Q_{\xi}^{t s}(\mathbf{v}, \xi(\boldsymbol{\omega}))-\sum_{r \in \mathcal{R}} \sum_{k \in \mathcal{G}_{t, n}}\left(c_{k t}^{r} x_{n t}^{k r}+e_{k t} y_{n t}^{k}\right)\right) \\
& \geq \max \sum_{s^{\prime} \in \mathcal{S}_{t-1}} p_{s^{\prime}}^{t-1} \times \sum_{s \in \mathcal{S}_{t}} p_{s \mid s^{\prime}}^{t} Q_{\xi}^{t s}(\mathbf{v}, \xi(\boldsymbol{\omega}))-\sum_{r \in \mathcal{R}} \sum_{k \in \mathcal{G}_{t, n}}\left(c_{k t}^{r} x_{n t}^{k r}+e_{k t} y_{n t}^{k}\right) \\
& =\max \sum_{s \in \mathcal{S}_{t}} \sum_{s^{\prime} \in \mathcal{S}_{t-1}} p_{s^{\prime}}^{t-1} \times p_{s s s^{\prime}}^{t} Q_{\xi}^{t s}(\mathbf{v}, \xi(\boldsymbol{\omega}))-\sum_{r \in \mathcal{R}} \sum_{k \in \mathcal{G}_{t, n}}\left(c_{k t}^{r} x_{n t}^{k r}+e_{k t} y_{n t}^{k}\right) \\
& =\max \sum_{s \in \mathcal{S}_{t}} p_{s}^{t} \times Q_{\xi}^{t s}(\mathbf{v}, \xi(\boldsymbol{\omega}))-\sum_{r \in \mathcal{R}} \sum_{k \in \mathcal{G}_{t, n}}\left(c_{k t}^{r} x_{n t}^{k r}+e_{k t} y_{n t}^{k}\right)
\end{aligned}
$$

In case II, $E P_{t, n}^{m}$ is given by Eq. (42). Similarly, the terms $\mathcal{G}_{t, n}^{\mathrm{OUT}}, \mathcal{G}_{t, n}^{\mathrm{SOLD}}, \mathcal{G}_{t, n}^{\mathrm{IN}}$ and $\mathcal{G}_{t, n}^{\mathrm{NEW}}$ are removed and then $E P_{t, n}^{m}$ is given by:

$$
E P_{t, n}^{m}=\max \sum_{s \in \mathcal{S}_{t}} p_{s}^{t} Q_{\xi}^{t s}(\mathbf{v}, \xi(\boldsymbol{\omega}))-\sum_{r \in \mathcal{R}} \sum_{k \in \mathcal{G}_{t, n}}\left(c_{k t}^{r} x_{n t}^{k r}+e_{k t} y_{n t}^{k r}\right)
$$

Therefore, $E P_{t, n}^{m}$ in case $\mathrm{I} \geq E P_{t, n}^{m}$ in case II. 
Table 1 Container shipment demand scenarios for illustrative example

\begin{tabular}{lccc||ccc}
\hline & \multicolumn{3}{c||}{ Year 1 } & \multicolumn{3}{c}{ Year 2 } \\
\cline { 2 - 7 } O-D pair & L & M & H & L & M & H \\
\hline PS $\rightarrow$ SH & 1000 & 2000 & 3000 & 1500 & 2500 & 3500 \\
\hline SH $\rightarrow$ YT & 800 & 1000 & 1500 & 1200 & 2000 & 2500 \\
\hline YT $\rightarrow$ HK & 1000 & 1500 & 2000 & 1500 & 2000 & 2500 \\
\hline
\end{tabular}

Table 2 Port calling sequence and number code for each route

\begin{tabular}{ll}
\hline Route & \multicolumn{1}{c}{ Port Calling Sequence and Number Code } \\
\hline CCX & Los Angeles/Oakland/Pusan/Dalian/Xingang/Qingdao/Ningbo/Shanghai \\
& /Pusan/Los Angles (1-2-3-4-5-6-7-8-9-1) \\
CPX & Shanghai/Ningbo/Shekou/Singapore/Karachi/Mundra/Penang/PortKelang \\
& /Singapore/Hong Kong/Shanghai (1-2-3-4-5-6-7-8-9-10-1) \\
GIS & Singapore/Port Kelang/Nhava Sheva/Karachi/Jebel Ali/Bandar Abbas \\
& /Jebel Ali/Mundra/Cochin/Singapore (1-2-3-4-5-6-7-8-9-1) \\
IDX & Colombo/Tuticorin/Cochin/Nhava Sheva/Mundra/Suez/Barcelona/NewYork \\
& /Norfolk/Charleston/Barcelona/Suez/Colombo (1-2-3-4-5-6-7-8-9-10-11-12- \\
& 1) \\
NCE & New York/Norfolk/Savannah/Panama/Pusan/Dalian/Xingang/Qingdao \\
& /Ningbo/Shanghai/Panama/New York (1-2-3-4-5-6-7-8-9-10-11-1) \\
NZX & Singapore/Port Kelang/Brisbane/Auckland/Napier/Lyttelton/Wellington/ \\
& Brisbane/Singapore (1-2-3-4-5-6-7-8-1) \\
SCE & New York/Norfolk/Savannah/Panama/Kaohsiung/Shekou/Hong Kong \\
& /Panama/New York (1-2-3-4-5-6-7-8-1) \\
UKX & Southampton/Hull/Grangemouth/Southampton (1-2-3-1) \\
\hline
\end{tabular}


Table 3 Distance of each leg in a ship route

\begin{tabular}{|c|c|c|c|c|c|c|}
\hline Route & \multicolumn{6}{|c|}{ Distance (nautical miles) } \\
\hline $\mathrm{CCX}$ & \multicolumn{6}{|c|}{$360-4$ 978-523-209-408-390-111-456-5 289} \\
\hline CPX & \multicolumn{6}{|c|}{$111-740-1$ 423-2 881-213-2474-165-198-1422-787 } \\
\hline GIS & \multicolumn{6}{|c|}{$198-2$ 247-498-713-152-152-890-915-1848 } \\
\hline IDX & \multicolumn{6}{|c|}{ 153-225-723-372-2 809-1 673-3 741-273-402-4 170-1 673-3 394} \\
\hline $\mathrm{NCE}$ & \multicolumn{6}{|c|}{$273-505-982-13$ 831-523-209-408-390-111-13 565-1359 } \\
\hline $\mathrm{NZX}$ & \multicolumn{6}{|c|}{$198-3$ 880-1 303-523-329-175-1 379-3 685} \\
\hline SCE & \multicolumn{6}{|c|}{ 273-505-982-12 949-366-26-12 788-1359 } \\
\hline UKX & \multicolumn{6}{|l|}{$315-243-511$} \\
\hline \multicolumn{7}{|c|}{$\begin{array}{l}\text { Source: The port distances are from the website: } \\
\text { http://www.searates.com/reference/portdistance/ }\end{array}$} \\
\hline \multicolumn{7}{|c|}{ Table 4 Ship data } \\
\hline \multirow{2}{*}{ Item } & & \multicolumn{5}{|c|}{ Ship types } \\
\hline & & 1 & 2 & 3 & 4 & 5 \\
\hline \multicolumn{2}{|c|}{ Ship size (TEUs) } & 2808 & 3218 & 4500 & 5714 & 8063 \\
\hline \multicolumn{2}{|c|}{ Design speed (knots) } & 21.0 & 22.0 & 24.2 & 24.6 & 25.2 \\
\hline \multicolumn{2}{|c|}{$\begin{array}{l}\text { Daily operating cost } \\
\left(\$ 10^{3}\right)\end{array}$} & 19.8 & 22.5 & 30.9 & 38.8 & 54.2 \\
\hline \multicolumn{2}{|c|}{$\begin{array}{l}\text { Daily lay-up cost } \\
\left(\$ 10^{3}\right)\end{array}$} & 2.8 & 3.2 & 4.5 & 6 & 8 \\
\hline \multicolumn{2}{|c|}{$\begin{array}{l}\text { Annual chartering out } \\
\text { rate (\$million) }\end{array}$} & 3.64 & 4.68 & 6.42 & 8.64 & 10.24 \\
\hline \multicolumn{2}{|c|}{$\begin{array}{l}\text { Annual chartering in rate } \\
\text { (\$million) }\end{array}$} & 4 & 5.2 & 7.0 & 9.4 & 12.0 \\
\hline \multicolumn{2}{|c|}{ Selling price (\$million) } & 85 & 105 & 175 & 225 & 345 \\
\hline \multicolumn{2}{|c|}{$\begin{array}{l}\text { Purchasing price } \\
\text { (\$million) }\end{array}$} & 135 & 155 & 215 & 275 & 385 \\
\hline
\end{tabular}


Table 5 Strategies proposed for each year

\begin{tabular}{cccc}
\hline Year & Strategy 1 & Strategy 2 & Strategy 3 \\
\hline 1 & $K_{2}^{1} K_{2}^{2} K_{9}^{3} K_{2}^{4} K_{12}^{5}$ & $K_{2}^{1} K_{2}^{2} K_{9}^{3} I_{1}^{3} K_{2}^{4} K_{12}^{5}$ & $K_{1}^{1} O_{1}^{1} K_{2}^{2} K_{9}^{3} I_{4}^{3} K_{2}^{4} K_{12}^{5}$ \\
2 & $K_{2}^{1} K_{2}^{2} K_{9}^{3} I_{5}^{3} K_{2}^{4} K_{12}^{5}$ & $K_{2}^{1} K_{2}^{2} K_{9}^{3} I_{2}^{3} K_{2}^{4} I_{2}^{4} K_{12}^{5}$ & $K_{2}^{1} K_{2}^{2} K_{9}^{3} I_{3}^{3} K_{2}^{4} I_{2}^{4} K_{12}^{5}$ \\
3 & $S_{1}^{1} K_{1}^{1} K_{2}^{2} K_{9}^{3} I_{4}^{3} K_{2}^{4} I_{2}^{4} K_{12}^{5}$ & $S_{2}^{1} K_{2}^{2} K_{9}^{3} B_{5}^{3} K_{2}^{4} K_{12}^{5}$ & $S_{1}^{1} K_{1}^{1} K_{2}^{2} K_{9}^{3} K_{2}^{4} I_{6}^{4} K_{12}^{5}$ \\
4 & $K_{1}^{1} K_{2}^{2} K_{9}^{3} I_{4}^{3} K_{2}^{4} I_{5}^{4} K_{12}^{5}$ & $K_{2}^{2} K_{14}^{3} K_{2}^{4} K_{12}^{5}$ & $K_{1}^{1} K_{2}^{2} K_{9}^{3} B_{5}^{3} K_{2}^{4} I_{3}^{4} K_{12}^{5}$ \\
5 & $S_{1}^{1} K_{2}^{2} K_{9}^{3} B_{5}^{3} K_{2}^{4} I_{3}^{4} K_{12}^{5}$ & $K_{2}^{2} K_{14}^{3} K_{2}^{4} I_{5}^{4} K_{12}^{5}$ & $K_{1}^{1} K_{2}^{2} K_{14}^{3} K_{2}^{4} I_{5}^{4} K_{12}^{5}$ \\
6 & $K_{2}^{2} K_{14}^{3} K_{2}^{4} I_{8}^{4} K_{12}^{5}$ & $S_{1}^{2} K_{1}^{2} K_{14}^{3} K_{2}^{4} B_{4}^{4} K_{12}^{5} I_{2}^{5}$ & $S_{1}^{1} K_{2}^{2} K_{14}^{3} K_{2}^{4} B_{4}^{4} K_{12}^{5}$ \\
7 & $S_{2}^{2} K_{14}^{3} K_{2}^{4} B_{4}^{4} K_{12}^{5} I_{3}^{5}$ & $K_{1}^{2} K_{14}^{3} K_{6}^{4} K_{12}^{5} I_{5}^{5}$ & $K_{2}^{2} K_{14}^{3} K_{6}^{4} K_{12}^{5} I_{5}^{5}$ \\
8 & $K_{14}^{3} K_{6}^{4} K_{12}^{5} I_{6}^{5}$ & $S_{1}^{2} K_{14}^{3} K_{6}^{4} K_{12}^{5} B_{6}^{5}$ & $S_{1}^{2} K_{1}^{2} K_{14}^{3} K_{6}^{4} K_{12}^{5} B_{6}^{5}$ \\
9 & $K_{14}^{3} K_{6}^{4} I_{4}^{4} K_{12}^{5} B_{3}^{5}$ & $K_{14}^{3} K_{6}^{4} K_{18}^{5}$ & $S_{1}^{2} K_{14}^{3} K_{6}^{4} K_{18}^{5}$ \\
10 & $K_{14}^{3} K_{6}^{4} K_{15}^{5} I_{5}^{5}$ & $K_{14}^{3} K_{6}^{4} I_{3}^{4} K_{18}^{5}$ & $K_{14}^{3} K_{6}^{4} I_{4}^{4} K_{18}^{5}$ \\
\hline
\end{tabular}


Table 6 Ship-to-route allocation of strategy $K_{2}^{1} K_{2}^{2} K_{9}^{3} I_{5}^{3} K_{2}^{4} K_{12}^{5}$ in case I for year 2

\begin{tabular}{|c|c|c|c|c|c|c|c|c|c|}
\hline $\begin{array}{l}\text { Demand } \\
\text { scenario }\end{array}$ & $\begin{array}{l}\text { Route } \\
\text { Ship } \\
\text { Type }\end{array}$ & $\mathrm{CCX}$ & CPX & GIS & IDX & $\mathrm{NCE}$ & $\mathrm{NZX}$ & SCE & UKX \\
\hline \multirow{5}{*}{.00 } & 1 & & & & & & & 2 & \\
\hline & 2 & & & & & & & 2 & \\
\hline & 3 & 3 & 3 & & & 5 & 3 & & \\
\hline & 4 & & & 1 & 1 & & & & \\
\hline & 5 & & & 1 & 3 & 4 & & 3 & 1 \\
\hline \multirow{5}{*}{ 异 } & 1 & & & & & & & 2 & \\
\hline & 2 & & & & & & & 2 & \\
\hline & 3 & 3 & 3 & & & 5 & 3 & & \\
\hline & 4 & & & & & 2 & & & \\
\hline & 5 & & & 2 & 4 & 2 & & 3 & 1 \\
\hline \multirow{5}{*}{ ב } & 1 & & & & & & & 2 & \\
\hline & 2 & & & 2 & & & & & \\
\hline & 3 & 3 & 3 & & & & 4 & 4 & \\
\hline & 4 & & & & & 1 & & 1 & \\
\hline & 5 & & & & 4 & 6 & & 1 & 1 \\
\hline
\end{tabular}


Table 7 Ship-to-route allocation of strategy $K_{2}^{1} K_{2}^{2} K_{9}^{3} I_{5}^{3} K_{2}^{4} K_{12}^{5}$ in case II for year 2

\begin{tabular}{|c|c|c|c|c|c|c|c|c|}
\hline $\begin{array}{l}\text { Route } \\
\text { Ship } \\
\text { Type }\end{array}$ & CCX & CPX & $\overline{\text { GIS }}$ & IDX & $\mathrm{NCE}$ & $\overline{\mathrm{NZX}}$ & $\overline{\mathrm{SCE}}$ & UKX \\
\hline 1 & & & & & & & 2 & \\
\hline 2 & & & & & & & 2 & \\
\hline 3 & 3 & 3 & & 2 & 2 & 3 & 1 & \\
\hline 4 & & & & & 2 & & & \\
\hline 5 & & & & 3 & 4 & & 2 & 1 \\
\hline
\end{tabular}




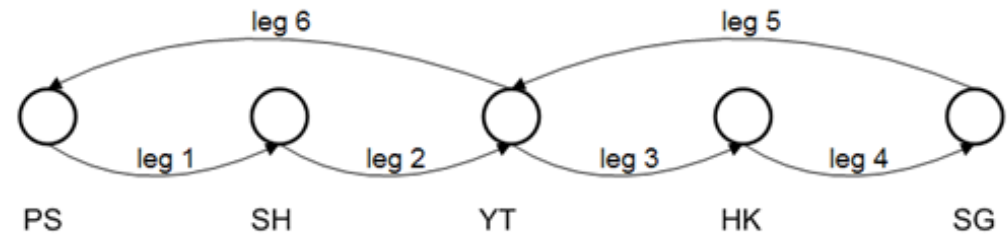

Figure 1 A liner ship route

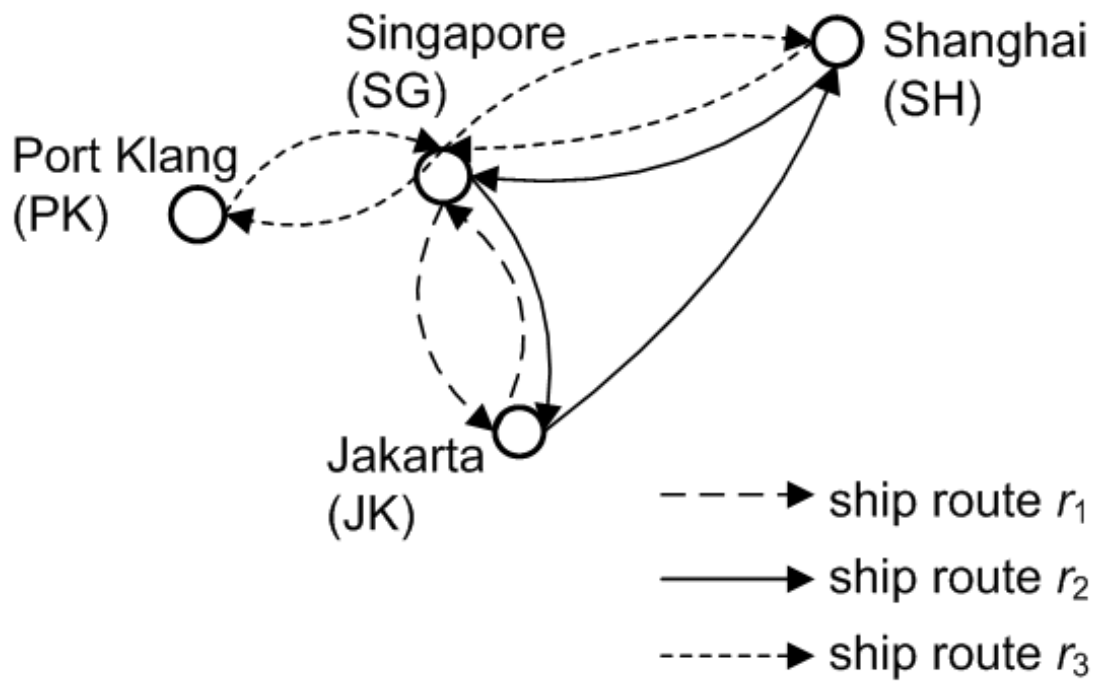

Figure 2 Three liner ship routes

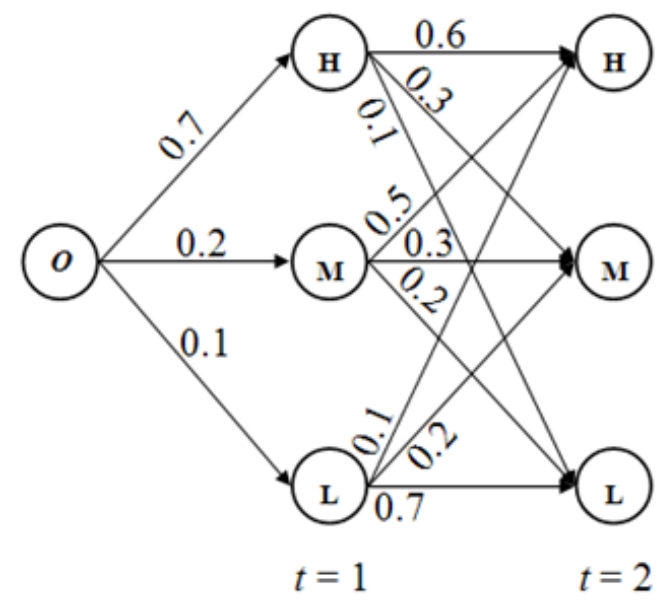

Figure 3 A two-layer scenario tree 


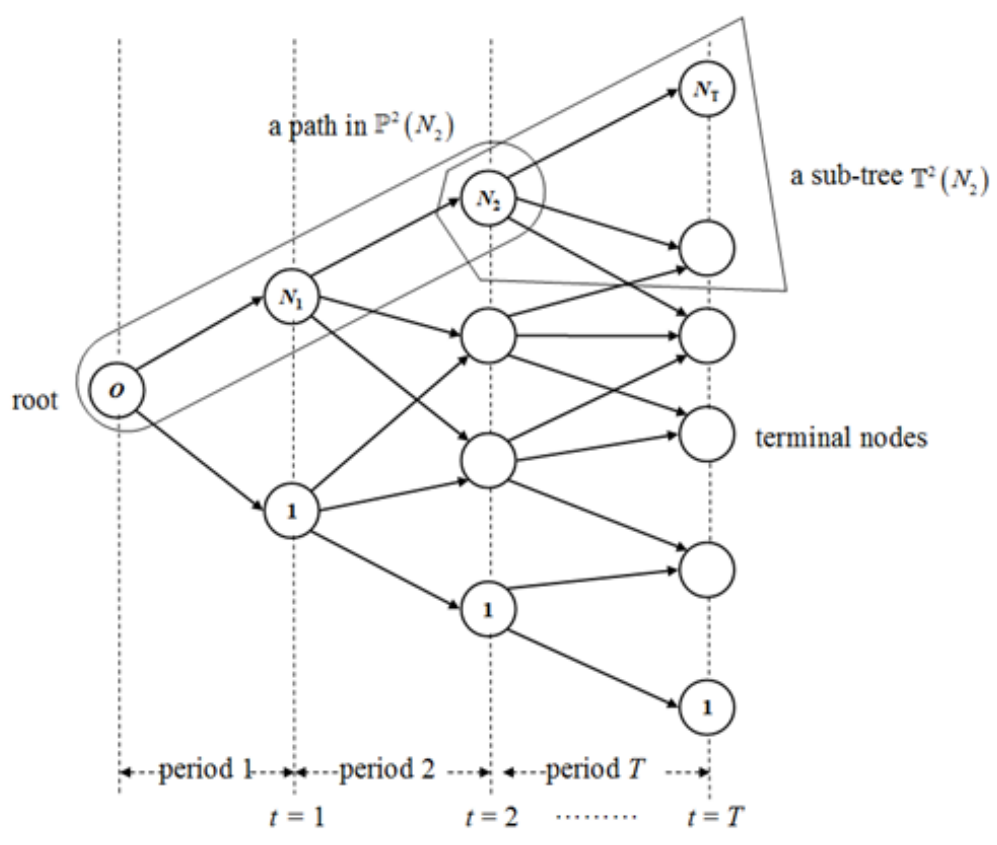

Figure 4 Decision tree for fleet development plan in MPLSFP problem

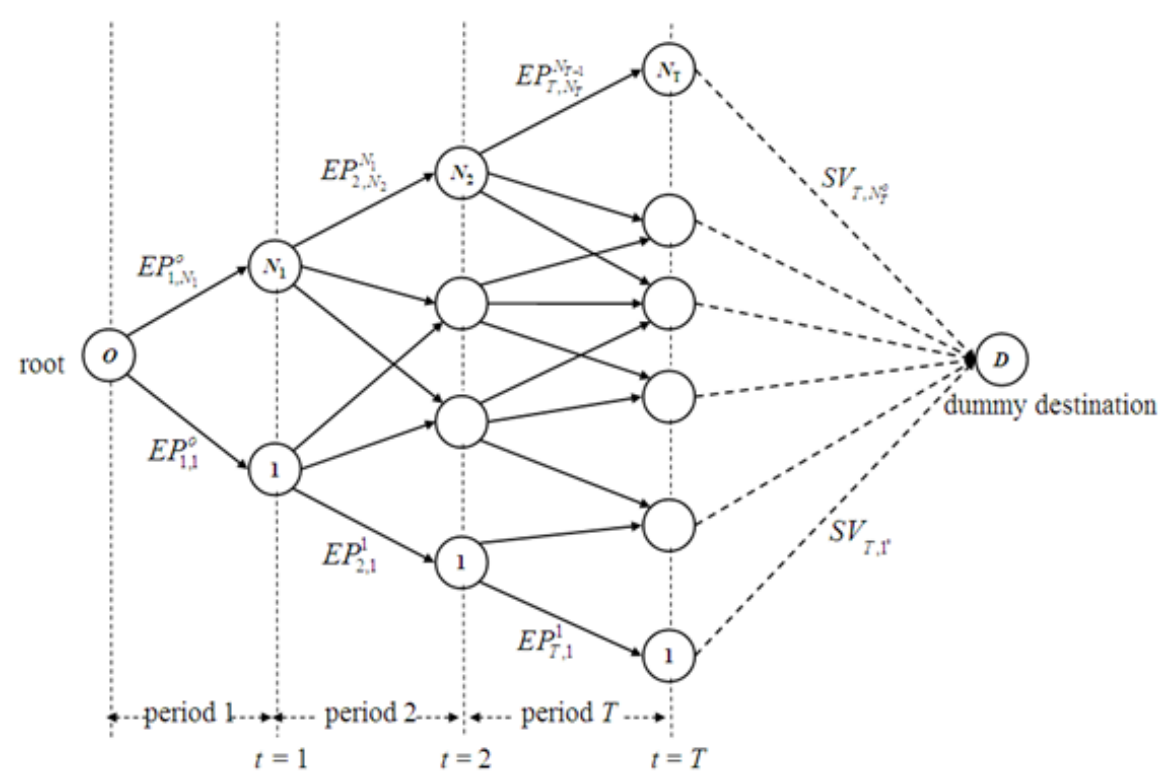

Figure 5 An acyclic network representation of the MPLSFP problem 


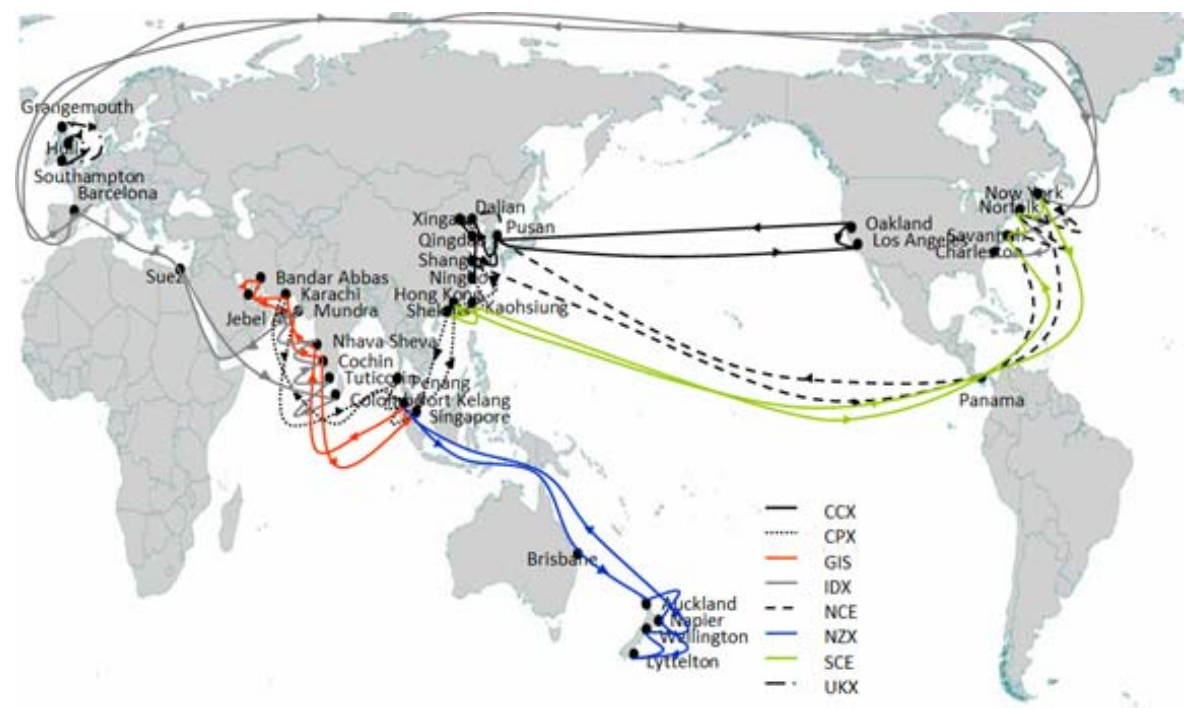

Figure 6 Liner shipping network for the numerical example

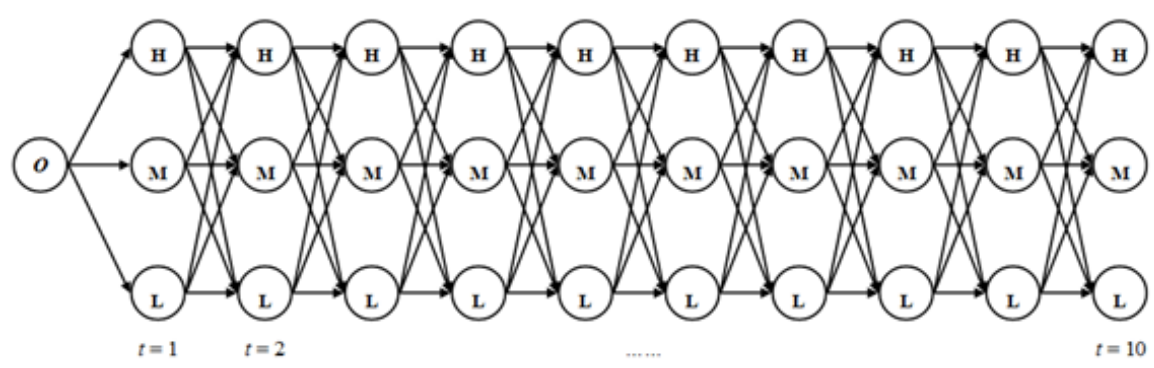

Figure 7 Scenario tree for the numerical example 


\section{Biography}

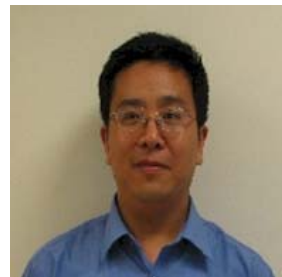

Dr. Qiang Meng is an Associate Professor in Department of Civil and Environmental Engineering at National University of Singapore. He is also the track leader on Shipping \& Logistics Transportation in Centre for Maritime Studies of National University of Singapore. He acquired $\mathrm{PhD}$ in Civil Engineering from Hong Kong University of Science \& Technology in 2000. His research expertise includes transportation network modeling and optimization, shipping network analysis and quantitative risk analysis.

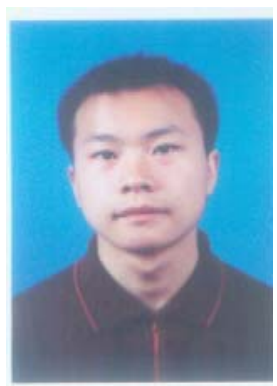

Dr. Tingsong Wang is an Associate Professor in School of Economics and Management of Wuhan University. He acquired PhD in Department of Civil and Environmental Engineering from National University of Singapore in 2012. Dr Wang specializes in modeling and optimization of liner shipping planning.

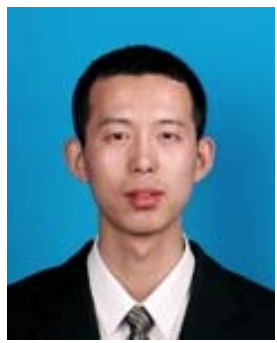

Dr. Shuaian Wang is a lecturer in School of Mathematics and Applied Statistics of University of Wollongong. His research interests include liner shipping network analysis, transportation network modeling and stochastic programming. 